\title{
The Art of the Pivot: How New Ventures Manage Identification Relationships with Stakeholders as they Change Direction
}

\author{
Christian E. Hampel \\ Imperial College London \\ c.hampel@imperial.ac.uk \\ Paul Tracey \\ University of Cambridge and University of Melbourne \\ p.tracey@jbs.cam.ac.uk \\ Klaus Weber \\ Northwestern University \\ klausweber@kellogg.northwestern.edu
}

\section{Acknowledgments}

We would like to thank Valentina Assenova, Erkko Autio, Marya Besharov, Kevin Corley, Stephanie Creary, Elena Dalpiaz, Aline Gatignon, Jennifer Howard-Grenville, Jax Kirtley, Madeline Toubiana, Tyler Wry and participants at the Cambridge Judge OTIS paper development workshop, the Oxford Saïd Business School (SBS) Write Club, the SBS PhD reading group, the Kellogg social movements reading group, and the Imperial College I\&E PDW for their valuable feedback. We also thank audiences at the Oxford Reputation Symposium 2016, the Academy of Management Annual Meeting 2016, the Management Department at Wharton, Schulich School of Business, and Imperial College London. We are also grateful to the members of Impossible and of the community for sharing their experiences with us. Finally, we extend our special gratitude to associate editor Eero Vaara and the three reviewers for their constructive and encouraging feedback and guidance. This manuscript is based on the first author's dissertation. A PhD scholarship from the Economic and Social Research Council (grant number: 1162930) supported this study. 


\section{The Art of the Pivot: How New Ventures Manage Identification Relationships with Stakeholders as they Change Direction}

Many new ventures have to pivot - radically transform what they are about - because their original approach has failed. However, pivoting risks disrupting relationships with key stakeholders, such as user communities, who identify with ventures. Stakeholders may respond by withdrawing support and starving ventures of the resources needed to thrive. This can pose an existential threat to ventures, yet it is unclear how they can manage this problem. To explore this important phenomenon, we conduct a qualitative process study of The Impossible Project, a photography venture which encountered significant resistance from its user community as it pivoted from an analog focus to an analog-digital positioning. We develop a process model of stakeholder identification management that reveals how ventures can use identification reset work to defuse tensions with stakeholders whose identification with the venture is threatened. A core finding is that ventures can remove the affective hostility of stakeholders and rebuild connections with many of them by exposing their struggles, thus creating a bond focused around these shared experiences. We offer contributions to scholarship on identification management, user community identification, and pivoting.

Keyword list: entrepreneurial pivoting; organizational identification; user communities; stakeholders; 
New ventures, which are frequently credited with boundless vision yet are usually resource constrained, are often reliant on stakeholders who identify with them. These stakeholders feel a sense of "oneness" with the venture, perceiving it to represent a key part of "who they are" (Ashforth, Harrison, \& Corley, 2008). This form of identification may characterize venture relationships with a range of stakeholders, including specialist retailers and distributors, special-interest financiers, artisanal producers and user communities. Such stakeholders are particularly valuable not only because they may constitute key sources of revenue, but because they provide resources such as publicity, market information and technical support that new ventures could not otherwise access or afford (Harrison \& Corley, 2011; Weber, Heinze, \& DeSoucey, 2008). For example, the fashion venture Threadless relies on its artistic community to design and market its outfits, with only a small proportion remunerated for their efforts (Lakhani \& Kanji, 2008). However, when stakeholders' identification with an organization is threatened, they may abandon or even come to oppose it (Gutierrez, Howard-Grenville, \& Scully, 2010; Petriglieri, 2015). While the triggers may vary, these identification threats are most often experienced by stakeholders when organizations engage in radical change (Kreiner, Hollensbe, Sheep, Smith, \& Kataria, 2015). Pivoting represents an especially radical type of organizational change for new ventures. A pivot is "a structured course correction designed to test a new fundamental hypothesis" about a venture (Ries, 2011:149). It happens when resource-constrained ventures come to view their current model and trajectory as unsustainable, and take the decision to transform themselves in an effort to survive and grow (Grimes, 2018; Kunisch, Bartunek, Mueller, \& Huy, 2017; Nicholls-Nixon, Cooper, \& Woo, 2000). Pivoting is common - new venture creation is complex and entrepreneurs rarely get it 'right' first time - but it has profound consequences nonetheless: when a new venture pivots, it fundamentally changes its strategy, identity and overriding goals (Drori, Honig, \& Sheaffer, 2009; Nag, Corley, \& 
Gioia, 2007). However, because stakeholders who identify with a particular venture tend to have such strong and specific expectations about it, this kind of radical transformation can unsettle or even alienate them (Garud, Schildt, \& Lant, 2014; Nag et al., 2007). For example, Berlin-based venture SoundCloud morphed from "a hangout for DJs (...) to a commercial platform for established artists to share their music" that then strictly enforced copyright among DJs (Cook, 2015:1). This pivot left "influential users (...) feeling alienated” and SoundCloud struggled financially (Cook, 2015:1), leading the venture to "cut about 40 per cent of its workforce (...) amid concerns it is running out of cash" (Ram, 2017).

As this example highlights, there is "a core problem inherent in pivoting" (Nobel, 2011:2) that may present new ventures with a thorny dilemma: they need to radically change direction to attract new audiences as their original approach has failed, but by pivoting they risk alienating the stakeholders who identify with them and on whom they rely for key resources. In these circumstances, ventures face the delicate task of managing relationships with this crucial stakeholder group as they switch tack.

Research has made much progress in showing how established organizations manage threats to the identification of employees (Ashforth et al., 2008; Besharov, 2014; Petriglieri, 2015). However, it is unclear how new ventures manage threats to the identification of external stakeholders over whom they have limited control (Jawahar \& McLaughlin, 2001), a particularly challenging task for resource constrained new ventures enacting a pivot. To shed light on this process, we study 1) the potential consequences of pivots for new ventures that rely on stakeholders who identify with them, and 2) how new ventures manage relations with these stakeholders during pivots.

We investigate these issues through a qualitative, inductive process study of "The Impossible Project” (hereafter: Impossible), which pivoted from an analog instant film producer focused on a niche community, to an analog-digital photography company focused 
on making analog photography relevant to the digital world and mass-market customers. Our study centers on how Impossible's "user community" (Von Hippel, 2001) - a key stakeholder group - responded to the venture's decision to move in this fundamentally new direction.

Based on our analysis, we develop a process model of stakeholder identification management during new venture pivoting. The starting point for the model is the enactment of a pivot by a new venture. Our analysis suggests that, following this radical change of direction, the identification of key stakeholders is threatened. This leads these stakeholders to challenge the venture either by attacking it outright (if they feel betrayed by the new focus) or by doubting it (if they feel anxious about the new focus). Crucially, we find that ventures can employ identification reset work to defuse identification threats and transition stakeholders to a new identification relationship. Specifically, identification reset work involves (1) seeking empathy for venture challenges, thus exposing its struggles, and (2) mythologizing the technology and the venture's commitment to its products, thus passionately idealizing the importance and scale of its efforts to overcome its struggles. By creating a bond with stakeholders around these shared challenges, the venture is able to emotionally reconnect with many of the stakeholders whose identification is threatened, nudging them to drop their opposition to the venture or to resume their support for it. Although a small number of stakeholders may remain hostile, we show that this work nonetheless allows the venture to resolve its identification crisis and complete the pivot.

In our case, seeking empathy and mythologizing were strategies enacted by Impossible in response to the reactions of its community. It is important to note that the nature and intensity of these reactions may vary depending on the relationship between the venture and its stakeholders and the circumstances surrounding the pivot. Nonetheless, the types of identification reset work that we identify could potentially be used to address a range of hostile stakeholder reactions. 
We make three contributions to scholarship on identification management, user community identification, and pivoting. First, through a model of stakeholder identification management, we reveal how new ventures can manage identification threats among external stakeholders as they pivot. At the core of our model is the concept of identification reset work, which explains how new ventures can overcome identification problems with external stakeholders by invoking shared struggles. Unlike identification management in established organizations (Besharov, 2014; Fiol, 2002; Petriglieri, 2015), this primarily involves revealing the venture's challenges and vulnerabilities rather than showcasing the venture's strengths.

Second, we contribute to scholarship on user communities. Research to date has shed important light on how organizations construct and maintain such communities (Harrison \& Corley, 2011; Von Hippel, 2001; Weber et al., 2008). We build on this research by exploring the dynamics of user community identification. This allows us to reveal a potential dark side of user communities and the process through which they may turn against new ventures.

Finally, we contribute to nascent scholarship on the important phenomenon of new venture pivoting by theorizing two key types of pivots - early-stage "conceptual pivots" and later-stage "live pivots" (on which this case focuses) - and uncovering the contrasting challenges inherent in each of them (Grimes, 2018; McMullen, 2017; Nobel, 2011).

\section{THEORETICAL BACKGROUND}

\section{Stakeholder Identification and Identification Management}

Organizational identity is an organization's "self-definition of 'who we are"” (Albert \& Whetten, 1985; Dutton \& Dukerich, 1991; Harrison \& Corley, 2011). It concerns the central, continuous and distinctive aspects of an organization (Albert \& Whetten, 1985;

Gioia, Patvardhan, Hamilton, \& Corley, 2013). Scholars have devoted considerable attention to studying how organizations create (e.g., Gioia, Price, Hamilton, \& Thomas, 2010), maintain (e.g., Kreiner et al., 2015) and change (e.g., Corley \& Gioia, 2004) their identities. 
More recently, attention has turned to the identity dynamics of new ventures, with a recognition that these are different from established organizations. A core insight of this nascent body of research is that new ventures often have to revise their identities as they evolve to gain resources from new stakeholders (Fisher, Kotha, \& Lahiri, 2016; Navis \& Glynn, 2011).

Scholarship on organizational identification is related to, but distinct from, organizational identity research (Ashforth et al., 2008). Organizational identification happens when individuals' beliefs about an organization "become self-referential or self-defining" (Pratt, 1998:179) as they regard their own identity to overlap with the organization's identity; in other words, they believe that they have "the same attributes" as the organization (Ashforth et al., 2008). Thus, while research on organizational identity explores the nature and evolution of identity at the organizational level, research on organizational identification explores how individuals relate to an organization, and is situated at a relational, meso-level.

Organizational identification scholarship represents a growing field of study comprising two main strands. The first strand, and the main focus of research to date, seeks to conceptualize distinct types of identification and to explain why individuals relate to organizations in particular ways (Cornwell, Howard-Grenville, \& Hampel, 2018; Mael \& Ashforth, 1992). More recently, a second strand has started to explore the management of organizational identification (Gutierrez et al., 2010; Pratt, 2000). This important, but relatively under-researched, conversation investigates organizations' efforts to influence how their stakeholders relate to them (Bartel, Baldi, \& Dukerich, 2016; Besharov, 2014; Petriglieri, 2015; Pratt, 2000). This is the theoretical conversation to which our study connects. It is a conversation that intersects with the extensive literature on stakeholders and organizations (see Parmar et al., 2010, for a review), as well as the smaller body of work on entrepreneurial stakeholders (e.g., Dew \& Sarasvathy, 2007; Mitchell \& Cohen, 2006). 
Existing research on identification management has focused on how established organizations respond when their internal stakeholders' (i.e., employees) identification is threatened. In these circumstances, the result can be stakeholder deidentification - when individuals lose their personal connection with the organization and disengage from it, or disidentification - when individuals identify in opposition to the organization and contest its new direction (Elsbach \& Bhattacharya, 2001; Pratt, 2000). The literature suggests that organizations can respond to these threats in two main ways: by highlighting positive organizational attributes (Petriglieri, 2015; Pratt, 2000); and/or deploying internal processes to re-establish stakeholder identification (Besharov, 2014; Petriglieri, 2015). These are important findings that have pushed the boundaries of identification management research. However, the insights offered may not apply to new ventures facing identification challenges from external stakeholders: the dynamics of such relationships are different, characterized by a high degree of venture dependency on these stakeholders, but also a low degree of venture control over them (Jawahar \& McLaughlin, 2001).

Specifically, because new ventures are resource-constrained, they often rely for resources on stakeholders who identify strongly with them. At the extreme, such stakeholders see the venture as positioned at the center of a community with shared goals rather than simply as a service provider or investment opportunity (Harrison \& Corley, 2011; HowardGrenville, Metzger, \& Meyer, 2013). Consequently, they may decide to support new ventures through privileged or free access to resources, from finance and technical knowledge to visibility and sales (Harrison \& Corley, 2011). Ventures can forge identification-based relationships with a variety of such stakeholders, such as specialist retailers and distributors, special-interest financiers, artisanal producers, and user communities (Harrison \& Corley, 2011; Massa, Helms, Voronov, \& Wang, 2017; Von Hippel, 2001; Weber et al., 2008). 
While the resources provided by stakeholders who identify with ventures can play a key role in new venture survival and growth, this group also poses a risk when new ventures experience radical change. This is because these stakeholders tend to have very clear expectations about how the venture is 'supposed' to behave (Eury, Kreiner, Trevino, \& Gioia, 2018; Petriglieri, 2015). Research has shown that when an organization diverges from expectations, stakeholders who identify with it will be prompted to challenge the organization (Gutierrez et al., 2010), leading to deidentification or disidentification (Elsbach \& Bhattacharya, 2001; Pratt, 2000). Because new ventures often depend on such stakeholders for resources, reactions of this kind may jeopardize their very survival. This renders it particularly important for new ventures to carefully manage these stakeholder relationships and to defuse any tensions that occur.

We focus in this paper on stakeholders who are members of a "user community" - a collective of users who engage intensively with a given product, derive personal benefit or enjoyment from that product, and collaborate with producers to test and refine it (Harrison \& Corley, 2011; Von Hippel, 2001). Members of user communities are often portrayed as having especially meaningful, identification-based relationships with ventures: they not only staunchly support a given venture because they feel a special connection to it (HowardGrenville et al., 2013; Lakhani \& Kanji, 2008; Weber et al., 2008), but are also willing to advocate for it and make sacrifices on its behalf (Harrison \& Corley, 2011). Scholars have shown how ventures foster user communities and how they derive benefit from them (Harrison \& Corley, 2011; Von Hippel, 2001; Weber et al., 2008). Interestingly, however, the identification dynamics of these communities have not been systematically examined.

In sum, new ventures often rely heavily on external stakeholders such as user communities who identify strongly with them. Yet it is unclear how ventures can respond when these stakeholders experience a threat to their identification. This is particularly likely 
to happen when ventures engage in radical change. In the next section, we turn to the specific type of radical change, pivoting, with which we are concerned in this study - where the dynamics of new venture identification may surface in an especially dramatic fashion.

\section{New Venture Pivoting}

Pivoting has emerged as one of the most important and widely applied concepts in the startup community (Klebahn \& O’Connor, 2011; Nobel, 2011; Penenberg, 2012), but has only recently begun to receive attention from management researchers. A pivot occurs when a new venture comes to believe that its current model is not viable, and that it needs to fundamentally change the nature of the business in order to survive and grow (Grimes, 2018; Ries, 2011). A pivot leads the venture to alter its core approach, usually involving a change to its strategy, identity and goals (Ries, 2011). Many new ventures decide to pivot - a wellknown example is Flickr, which pivoted from a game developer to an online photo-sharing platform (Nazar, 2013).

A pivot is a distinct type of strategic change. It differs from conventional strategic change in the organizational literature in two important respects (cf., Kunisch et al., 2017). First, a pivot concerns a new venture - "an organization in its early years of existence" - in which leaders engage directly with the, usually small, team of people who belong to it to transform the venture (Garud et al., 2014; Zimmerman \& Zeitz, 2002:414). In contrast, strategic change "has focused almost exclusively on (...) large, established firms" in which leaders have to navigate multiple layers of hierarchy and bureaucracy to implement the change (Huy, Corley, \& Kraatz, 2014; Nicholls-Nixon et al., 2000:495). Second, new ventures are resource-constrained and often fragile. As the decision to pivot is usually taken in response to a belief that the venture's existing model is fundamentally flawed, its survival usually hinges on the successful execution of the pivot (Aldrich \& Fiol, 1994; Drori et al., 2009; Nag et al., 2007). By contrast, established organizations engage in strategic change for a variety of reasons, such as a loss of market share or the arrival of a new leader, and the 
success of the change process may not be a matter of organizational life or death, at least in the short term, as firms can put contingencies in place and may have the resources to plan for multiple outcomes (Gioia \& Chittipeddi, 1991; Huy et al., 2014).

New ventures can pivot at different points in their development. Some pivot at a very early stage, when they are essentially an idea in the entrepreneur's head (Grimes, 2018). Many others pivot at a later stage, when they have pursued their initial approach for months or even years and attracted a base of loyal stakeholders (Drori et al., 2009; Nag et al., 2007). In the latter case, the new venture abandons its initial approach but at the same time needs to carefully manage relations with its stakeholders (Garud et al., 2014; Nobel, 2011), as the cautionary tale of SoundCloud, summarized above, suggests.

\section{The Puzzle: How New Ventures Manage Identification Relationships with Stakeholders as they Pivot}

New ventures that pivot often face a profound dilemma: they decide to pivot because they believe that their original approach has failed and they need to move in a new direction (Grimes, 2018; Nag et al., 2007); at the same time, pivots risk undermining the identification of key stakeholders on which they depend for resources (Drori et al., 2009; Garud et al., 2014; Nobel, 2011). This is the "core problem inherent in pivoting - the risk of looking disloyal (...) switching gears can feel almost like a betrayal” (Nobel, 2011:2). If key stakeholders who identify with the venture perceive such disloyalty and their support turns to hostility, then the new venture may collapse (Elder, 2016). Identification management research has offered crucial insights into how established organizations can diffuse tensions with internal stakeholders who experience threats to their identification (Besharov, 2014; Fiol, 2002; Petriglieri, 2015). However, it remains unclear how new ventures can respond when external stakeholders - on whom they rely for resources but over whom they can exert minimal control - experience threats to their identification as a result of strategic decisions deemed necessary by the venture for its survival. This represents a formidable task, 
particularly when the stakeholders in question are part of a community, such as a user community, with strong attachments to the venture. To illuminate this critical and thorny issue, we ask the following research questions: What are the potential consequences of pivoting for new ventures that rely on stakeholders who identify with them? How can new ventures manage relations with these stakeholders during pivots?

\section{METHODS}

To address our research questions, we conducted a process study of how Impossible's pivot affected a key stakeholder group - its user community - and how the venture managed the resulting identification tensions with this group from 2013 to 2016.

\section{Research Context}

Impossible is an analog instant photography venture. It was founded in 2008 to restart production of Polaroid film after the Polaroid Corporation went bankrupt (Bradshaw, 2009). Polaroid sold its production equipment to Impossible but it did not pass on the 'recipes' for the films, forcing Impossible to develop new films. This led to an experimental product with varying, and initially poor quality, results (Sax, 2016). Despite these problems, Impossible attracted much interest from the analog photography community and focused on this small niche. To do so it created the Pioneer program, whose 3,500 members - known as Pioneers received film earlier than general audiences, contributed to film testing, and obtained discounts on film. Pioneers played a key role by providing feedback on products, publicizing the venture on social media, and buying lots of film.

Impossible had been in a difficult financial position from the start as it had to sustain a large, former Polaroid factory with limited resources and film sales. It needed to grow to be profitable, but the analog instant photography niche proved too small. In 2013, the venture tried to address this problem by pivoting from a pure analog instant film provider focused on the niche analog community, to a company that sought to redefine analog instant photography in a digital world and target the mass-market (see Figure 1 for timeline). The pivot presented 
the venture with a strategic dilemma: while a mass-market focus promised sales growth and profitability in the medium-term, in the short-term it severely strained relations with its user community, many of whom turned against the venture and stopped buying film, thereby threatening its commercial viability. Impossible thus needed to appease its community to pivot successfully and create a profitable future. ${ }^{1}$

\section{----- INSERT FIGURE 1 ABOUT HERE -----}

\section{Data Collection}

To answer our research questions and triangulate our findings we collected qualitative data of three types: interviews, archival data and participant-observation (see Table 1).

\section{----- INSERT TABLE 1 ABOUT HERE -----}

Interviews. A first key data source is 74 interviews with Impossible employees and members of Impossible's user community. We conducted 35 interviews with Impossible staff, including its key executives, and five with Impossible retailers. These interviews focused on the perceived challenges Impossible faced, the changes to the venture, the venture's interactions with its community, and how community members responded.

The remaining 34 interviews were conducted with members of Impossible's user community. ${ }^{2}$ All 34 community members in our data set had originally identified with Impossible. These interviews focused on community members' interactions with Impossible, how they responded to Impossible's actions, and how their relationship with Impossible had evolved. We accessed these interviewees by first asking Impossible to suggest influential community members, then engaging in snowball sampling. We asked community members to suggest others who were influential in the community but held views that were different to

\footnotetext{
${ }^{1}$ In September 2017 - sometime after our focal period of 2013 to 2016 - Impossible got the opportunity to license the well-known Polaroid name and rebranded as "Polaroid Originals" (Mathies, 2017).

${ }^{2}$ We use the term "community member" to be consistent. Our informants also used the terms "Pioneers" or "fans" to denote these stakeholders from Impossible's user community who identified with and supported Impossible. As a result, informant quotes also include these terms when referring to community members.
} 
their own to gain the full spectrum of perspectives. Thus, we used "polar type" sampling to access extreme cases and help reveal key patterns (Eisenhardt \& Graebner, 2007).

We continued to conduct interviews until we reached theoretical saturation; i.e., when no new patterns emerged (Glaser \& Strauss, 2009). Interviews lasted 50 minutes on average and were recorded and transcribed. ${ }^{3}$

Archival data. We also collected a wealth of archival material that showed the actions of Impossible and its user community, as well as direct interactions between them. To better understand Impossible's actions and how it communicated these, we collected 650 newsletters that the venture sent to its subscribers, selected 131 key blog entries (out of c. 1,200) posted on its website, as well as 90 press releases and 388 minutes of film footage about Impossible. To better understand how members of the user community reacted to Impossible's actions and how the two interacted, the first author monitored Impossible's social media channels throughout the research period. This included tweets, Facebook posts, blog posts and podcasts. As Twitter was the key forum on which Impossible and the community interacted, we collected over 1,550 tweets, many of which showed interactions between Impossible and community members. Finally, we also collected press articles, books and documentaries about analog photography and Impossible for contextual information.

Participant observation data. A third key data source arose from the first author's eight weeks of participant observation at Impossible's Berlin head office (February to April 2014). Working as an unpaid intern within the marketing team, tasks varied widely from filing to data analysis. He engaged in c. 350 hours of participant observation at the office and joined social activities with the team. The first author kept a notebook and wrote down observations, many of which were followed up with community members and Impossible staff. In addition to daily field diary entries, he also wrote several memos over the period to

\footnotetext{
${ }^{3}$ We conducted all interviews in person, over the telephone or via Skype except for six e-mail interviews.
} 
reflect upon the key dynamics that he encountered. The participant observation led to valuable informal conversations, formal interviews, and insights that allowed the author team to nuance understanding of Impossible's actions and the rationale underpinning them. A key insight that emerged was the - often hostile - opposition that members of the user community exhibited towards the pivot and the challenges that the venture faced as a result.

\section{Data Analysis}

Given the limited understanding in current theory of how pivots affect stakeholders and how ventures manage interactions with these stakeholders, we drew on the principles of naturalistic enquiry to conduct an inductive, qualitative process study (Glaser \& Strauss, 2009; Langley, 1999; Lincoln \& Guba, 1985). Specifically, we employed key sensemaking strategies - grounding, organizing and replicating (Langley, 1999) - to move from raw data to theoretical constructs and our process model. We progressed through several stages.

Identify case trajectory and code venture's initial actions. To gain an overview of the progression of events, we first established a timeline or "chronology" of the venture's key activities during its pivot (Langley, 1999; see Figure 1). To ground our process study firmly in the phenomenon, we engaged in open coding. In a first step of this stage we identified the actions that Impossible took to enact the pivot, using in-vivo codes where possible (Langley, 1999). At this stage, we primarily coded interviews with Impossible staff, the first author's participant-observation, as well as those archival data that were produced by Impossible, such as newsletters and blog posts. By coding at the sentence- and paragraph-level, we first arrived at five first-order codes for enacting the pivot, such as "create provocative new products".

Code community reactions to the pivot. Another "grounding" stage (Langley, 1999) was coding for how members of Impossible's user community reacted to the pivot. To do so we drew primarily on interviews with community members and on social media data, such as Twitter. This alerted us to different reactions to Impossible's pivot. As many community members exhibited strong affective reactions, we coded separately for emotions, following 
Toubiana and Zietsma's (2017) approach. This involved (1) identifying the main emotive responses (betrayal and anxiety) based on a subset of the data, (2) selecting keywords for these based on our data and current research and (3) coding for these emotions. This process led to four user community-related first-order codes, such as "experience anxiety", which denoted the perception among a key group of community members that Impossible was no longer committed to them or their cherished technology.

Code venture's efforts to manage stakeholder identification. We next coded for Impossible's actions to manage relationships with community members in light of their negative reactions to the pivot. Once again we immersed ourselves in the data to ground our findings firmly in the evidence, and open coded relevant aspects of our data set accordingly (Langley, 1999). We drew in particular on interviews with Impossible employees, the first author's participant-observation, and public documents created by Impossible, such as newsletters, clips and blog posts. This led to seven first-order codes, such as "stress devotion to product", which denoted Impossible's actions to show how affectively and wholeheartedly the venture was invested in its film and in improving it.

Code community reactions to Impossible's efforts. We also coded for community members' reactions to the venture's identification management efforts, and once again separately coded for emotions using the approach outlined above. This led to five new firstorder codes, such as "feel reverence for film progress", in addition to the four initial community first-order codes which some members also exhibited at this point.

Combining all our first-order codes, we identified 21 recurring codes, at which we arrived after multiple iterations and the removal of repetitive codes. It is important to note that we placed emphasis on different data as we coded for venture actions and community members' reactions, but engaged in triangulation throughout. For example, while we primarily relied on staff interviews, participant observation and venture-related archival data 
to identify venture actions, we used community member interviews and social media data for triangulation. We paid particular attention to evidence of venture-user community member interactions in social media posts and interviews in order to gain insight into the processual dynamics at the heart of our case, and to ascertain the impact of the venture's actions on community members' identification. Throughout, we tried to bracket our theoretical preconceptions and in doing so arrived at counterintuitive codes. For example, one first-order code is "stress technical struggles" which denoted Impossible's efforts to communicate to its user community the problems it faced in producing film, including its own limitations. This surprised us as we expected the venture to show its strengths instead of exposing weaknesses. We show quotes for each first-order code across the findings and in supplementary data tables (see Figure 2 for data structure and Table 2 for additional supporting data).

\section{----- INSERT FIGURE 2 ABOUT HERE -----}

Identify second-order themes. Once we had identified the first-order codes, we looked for relationships between them to identify broader, theoretically informed, and more general themes. This involved moving from a focus on "grounding" strategies to a focus on "organizing" strategies that systematically represented the data and the key connections between first-order codes (Langley, 1999). Thus, we shifted from closely interrogating the data to cycling between data, theory and emerging patterns. Through this analysis, we arrived at five venture-related and four user community-related second-order themes. For example, we concluded that "experience anxiety" and "stress no longer feeling valued" constituted the second-order theme "doubt venture". The "organizing" strategy of creating narrative vignettes helped us in this process (Langley, 1999). We also consulted relevant scholarship, such as organizational identification research, which helped to unpack key dynamics in our data but did not fully explain them. To illustrate: identification scholarship helped us to recognize the distinct ways in which community members identified with Impossible (e.g., 
Elsbach \& Bhattacharya, 2001; Pratt, 2000) but it could not explain why they moved between key categories, such as from attacking the venture to disengaging from it.

Develop aggregate theoretical dimensions and process model. Once we had arrived at the second-order themes, we identified the three overarching aggregate theoretical dimensions that governed our data. We labelled the venture's actions "enact pivot" and "identification reset work", and the community members' responses "stakeholder reaction", 4 to capture their distinct focus. At this point, we closely interrogated the temporal trajectory of venture actions and stakeholder reactions. In particular, we engaged in the "replicating" strategy of temporal bracketing to identify how venture actions in one period affected community member reactions in the next period and vice versa (Langley, 1999). This involved visually mapping when actors engaged in activities or reacted to them, and iterating through possible models until we arrived at a final process model that could explain the underlying mechanisms (Langley, 1999; York, Hargrave, \& Pacheco, 2016).

\section{FROM PIVOT TO PROTEST? THE PROCESS OF STAKEHOLDER IDENTIFICATION MANAGEMENT AT IMPOSSIBLE, 2013-2016}

We now present our case analysis. The case unfolds over two phases (see Figure 3 for our model). For each phase we show the actions taken by Impossible and the reactions of Impossible's user community who originally identified with the venture.

\section{----- INSERT FIGURE 3 ABOUT HERE -----}

\section{Phase I: Starting the Pivot}

In April 2013 Impossible's founding team and board installed a new CEO who, crucially, had a track record in digital entrepreneurship, to enact the pivot and turn the venture around. With new leadership in place, Impossible started to pivot from a venture focused on the manufacture and supply of analog instant film serving a niche community of

\footnotetext{
${ }^{4}$ In our analysis, we do not include those community members who were indifferent to or supported the pivot. We focus on members who initially reacted negatively as we felt that they are the most theoretically interesting.
} 
analog photographers, to a company intent on redefining analog instant photography in a digital world by serving mass-market audiences (see Table 3 for an overview of the pivot). During this period in which it started the pivot, the venture actively promoted itself to new, mass-market audiences because achieving sales growth was deemed important for the venture's long-term viability. The pivot involved rapidly transforming the venture based on a redefinition of its core purpose. We found that enacting the pivot comprised two elements (see box on far left of Figure 3): make bold new identity claims and create radical new strategy.

Enact pivot (1): Make bold new identity claims. Impossible's pivot involved bold new claims as to "who we are". The venture abandoned its commitment to analog purity and instead embraced the digital world to start "a new chapter in the history of analog instant photography" (Press Release, 2013). A senior executive explained: "We are living in a digital world. Analog photography is part of this world" (\#47). ${ }^{5}$ The new identity claims consisted of two parts: shift to shape the future of analog and focus on lifestyle audiences.

Impossible emphasized that it was now intent on redefining the future of analog and made clear that this future involved tying into current digital trends. An executive explained:

"We are really tasked to defining the relevance for this beyond simply being vintage (...) to become a realistic, viable analog product for the future (...) less to the glorious past of Polaroid but to the glorious present of how people actually use images" (\#44).

During fieldwork, a focus on the future of analog was a recurring theme regularly invoked by employees. One explained that Impossible now "combines the good of the analog days and brings it to the twenty-first century with a digital aspect" (\#51)[.] An executive similarly explained that the future was about "merging the digital and the analog world" (\#45)[.]

Impossible also made bold new identity claims by focusing on lifestyle audiences. The venture came to see itself as part of the fashion, design and arts scene. It thus moved

\footnotetext{
${ }^{5}$ We assigned a number to each informant whom we interviewed.
} 
away from niche photography audiences in an effort to become a mass-market venture.

During fieldwork the first author observed first-hand the importance of the new focus:

"The office is buzzing with ideas which focus on moving beyond classic Polaroidstyle film and the analog community to reach the fashion-conscious crowd with edgier products that connect to the 21 st century" (Fieldnotes).

In an interview an employee was enthusiastic that Impossible was becoming "something that is not just interesting [to] the niche of photography experts but to people who are more interested in arts, in aesthetics, in lifestyle" (\#57)[.] Impossible stressed that it was "a favorite of the fashion crowd" as it had noted growing interest from this group (Press Release, 2014).

Enact pivot (2): Create radical new strategy. In lockstep with its identity overhaul, Impossible radically changed its strategy. The new strategy comprised three key elements: create provocative new products, refocus operations and shake up community activities.

A core element of Impossible's new strategy was to create provocative new products that fitted its new identity. While Impossible initially produced only analog films for vintage cameras, it now moved into hardware production - developing its own cameras and creating new analog-digital crossover devices to attract mass-market users. A milestone was the launch of the Instant Lab, which allowed users to turn iPhone pictures into analog prints. Impossible explained proudly that the device "merges the worlds between digital and analog photography” (Press Release, 2013). Employees stressed its importance: “The Instant Lab is the first real, serious thing that we have produced that is (...) not in any way retro, like the film could be considered. The Instant Lab is that bridge between analog and digital" (\#56).

In 2013 Impossible also launched an app that enabled users to manage their pictures and began releasing quirky special edition films with colored, round or patterned frames that radically departed from its original films. Staff stressed that these films were "a conscious attempt to move into a different direction" (\#54) and a "wild departure from the classic square white frame" to show the future of analog (Press Release, 2014). 
The radical new strategy also involved redesigning core elements of Impossible's operations. The venture moved its head office, created a new digital design team, closed stores that did not fit with the new positioning, and invested in film development - changes designed to support the shift to mass-market audiences. For example, an executive stressed the importance of moving to Berlin: "What better place to have a headquarters (...)? Right now Berlin is the center of world design" (\#44). Impossible also shifted resources from retail to R\&D: "our focus and (very high) investment is in our next generation of films (...) We have actually withdrawn from all our retail presences, except Paris” (Twitter, 2014). It also formed a "digital design team" in Berlin tasked with creating provocative new film designs and a radically overhauled website. In making these changes, Impossible recruited many people in new areas. At the same time some employees left, including many who had worked in its stores and some who chose not to transition to the 'new' Impossible.

Another element of Impossible's radically new strategy involved shaking up its community activities. Impossible had originally catered strongly to its niche user community but now refocused on the larger lifestyle segment. While highly active, community members were small in number. One employee illustrated this based on Impossible's Pioneer program: “Once we have sold to all our Pioneers, that's that market exhausted. (...) now we (...) focus on bringing new customers in" (\#56)[.]

As a result, Impossible scaled back its offering to community members, including its social media efforts (e.g., photo-sharing site Flickr) and the Pioneer program. It also relied less on the community for pictures for its website and advertising. One employee explained: "Impossible was very dependent on photography from the community (...) [now] we work with actual professional photographers” (\#57). Impossible also launched high profile collaborations that targeted the mass-market, and drew on the worlds of art, design, media 
and digital photography. For example, Impossible blogged that the singer Lana del Rey “struck a pose for us (...) on our brand-new Black \& White film” (Impossible Blog, 2014a).

Impossible continued its efforts to enact the pivot and to attract new audiences until the end of our study period in 2016 (as highlighted by the dotted line at the bottom of Figure 3). However, as outlined below, the venture soon had to simultaneously devote significant resources to managing and repairing relationships with its original user community due to the strong - and often highly negative - reactions of many community members to the pivot.

\section{Stakeholder Reactions}

Given that the venture was undergoing a major transformation, Impossible employees had expected some "pushback" during the pivot "as we pushed the ship towards bigger waters" (\#47). However, staff were surprised and alarmed at the strength of feeling among its user community. They observed with great concern that the venture's relationship with the community was being "warped or destroyed by this whole change" (\#53). This negative reaction was deeply problematic for the venture as the community played a key role for Impossible in a variety of areas, such as generating revenue and helping to publicize the venture (see Table 4 for quotes about the importance of the user community for Impossible). Specifically, community members responded to Impossible's pivot in two discrete ways: 1) by attacking the venture and 2) by doubting the venture (see ovals on center-left of Figure 3).

\section{----- INSERT TABLE 4 ABOUT HERE -----.}

Stakeholder reaction (1): Attack venture. One group of community members initially reacted to the pivot by becoming 'attackers'. They had previously identified with Impossible as the venture had been a key part of their identity. However, following the pivot they came to disidentify from Impossible as now their opposition to the venture became a key part of their identity (cf., Elsbach \& Bhattacharya, 2001). Attackers appeared to be motivated by a core emotion, namely a perception of betrayal. These feelings led this group to fight Impossible. Intriguingly, we found that the community members who exhibited this reaction 
had originally identified primarily on the basis of a sense of belonging to the user community around the venture (rather than primarily on the basis of the product itself).

One such attacker is Susan ${ }^{6}$, an entrepreneur who started to support Impossible shortly after it was founded. She identified with Impossible through the community:

"There was never a question of separation (...) we were the ones talking about it [Impossible], we were the ones telling our friends. (...) I think they did their best to take care of us as community members so that we would take care of them. We all wanted to see it succeed and we all felt like we had a stake in it" (\#30) [.]

When Impossible started to pivot, Susan said she was devastated: "it hit so hard. It's because we were all so invested in it emotionally, it was our life and our identity. (...) How do you identify with that [post-pivot Impossible]? I don't want to (...) totally shift with the changes at Impossible" (\#30). She was incensed that Impossible was willing to "completely drop (...) the community", feeling "anger" and "ire" at Impossible (\#30). Believing that this was an act of betrayal, she fought Impossible online and offline.

Thus, attackers perceived Impossible to have betrayed the user community. In their view, the venture had abandoned them by pivoting towards the digital world and mass-market lifestyle users. For example, one attacker said that he "felt betrayed (...) that they pulled the rug from under us" (\#31), while another observed feeling "bitter" about the pivot "[because] (...) I wanted them to be what they were initially, which is a part of the community" (\#6).

Attackers often publicly voiced their sense of betrayal in response to Impossible's new identity claims and its revised approach to relationships. One attacker reacted to Impossible's reduced community activities with intense emotion: "That's like a knife to my heart after the relationship we've had" (Twitter, 2014). Another articulated profound disagreement with Impossible's new focus on lifestyle audiences, voicing a sense of betrayal: "We spent all this time and money and now you're just basically spitting in our faces" (\#31).

\footnotetext{
${ }^{6}$ We have changed the names of the individuals featured in our vignettes to protect their anonymity.
} 
Attackers chose to fight Impossible publicly and chastise its behavior. Some also stopped sharing their expertise - they pointedly refused to give feedback on film and other Impossible products. Indeed, former community members seemed to exhibit the same passion previously used to support Impossible, but instead were redirecting it to condemn the venture. This included attacks through a variety of media, such as word-of-mouth, Twitter, Facebook, podcasts and blogs. The anger of attackers sometimes erupted in maelstroms that appeared frenzied: "It was one Saturday that the community just went crazy. Absolutely crazy. Hundreds of people were tweeting back towards Impossible to not make changes” (\#4).

One way in which attackers fought Impossible was by seeking to sour the overall mood surrounding the venture, as in this widely followed analog photography podcast: "Everybody hates it. The Impossible Project is going to fall flat on its face" (Pdexposures, 2014a). This often involved attacking Impossible in general, such as a community member who tweeted being “[d]isgusted with the whole company" (Twitter, 2014). A related approach involved attacking specific product features and launches. For example, one community member responded to a PR campaign that Impossible employed to attract new audiences by tweeting "HOLY. CRAP. What in the world is wrong with them?!" (Twitter, 2014). Finally, attackers reported boycotting Impossible to fight the perceived betrayal. A community member explained a widespread stance as follows: "I'm never buying Impossible again, don't buy Impossible” (\#23)[.] As each member's spending on Impossible products could run to thousands of dollars per year, this aggravated Impossible's financial problems.

Stakeholder reaction (2): Doubt venture. A second group of community members did not oppose the venture outright but came to doubt it. This sense of doubt ranged from finding Impossible's changes disconcerting and being on the cusp of turning hostile at one end of the spectrum, to being confused and hoping that more clarity would allow them to rebuild their relationship with the venture at the other end. Interestingly, unlike the attackers 
who originally identified with Impossible primarily on the basis of a sense of belonging to its user community, the doubters originally identified with Impossible primarily on the basis of its products. This group felt a sense of anxiety about the venture and its future commitment to a cherished product range. These feelings led doubters to express that they no longer felt valued by Impossible.

Clara is one of those who doubted Impossible during its pivot. Working in professional services, she started supporting Impossible shortly after it started: "When I first picked up that camera and that pack of film, I never anticipated how much I would be using it and how much that medium has become a part of my life" (\#14). She felt close to Impossible because of the product, but as the venture pivoted, she was:

"bewildered about what was going on (...) an unsettling time. People didn't really know. It seemed we had been part and parcel of it [Impossible] for three or four years and all of a sudden any opinions we might have had didn't seem to matter" (\#14).

This uncertainty as a result of the pivot created anxiety among a key group of community members: as Impossible was rapidly transforming, they worried about how they and their beloved products fitted into the picture. During fieldwork, the first author often saw how frustrated employees were about the anxiety that community members experienced and the deteriorating relations that ensued: "Everyone in the team is aware that Impossible's many changes over the last few months have confused and unsettled many Pioneers" (Fieldnotes).

Doubters were particularly concerned about the new material focus that Impossible adopted as it radically restructured its operations and launched products that deviated significantly from their expectations. One informant expressed a concern that was commonly held among doubters and demanded that Impossible allay their fears: "We are scared that something horrible is gonna happen and instant film is gonna die forever. (...) Impossible really have to go in and calm everybody's nerves" (\#4) [.] Similarly, another explained that: 
"a lot of people were fearing that the pictures they were going to see on the gallery would not be instant film anymore but basically digital images made on instant film" (\#12).

Impossible's changes led doubters to complain openly that they no longer felt valued by the venture. However, while attackers fought Impossible outright, doubters were more willing to engage in dialogue. They were worried that there was less space for them due to the ongoing pivot and feared that Impossible would sacrifice their favorite analog products to pursue its commercial goals, as one explained: "I hope that in two to three years they don't forget who we are" (\#17). An employee was concerned that doubters felt unappreciated:

"People were disappointed (...) The old fans are really, really analog and they don't like this Instant Lab and all these digital things. (...) They think: "If they are going in this direction, we don't want to be part of it anymore so much" (\#64).

Relatedly, doubters complained publicly that Impossible no longer cared about the core products that community members loved - instead prioritizing faddish special edition films to drive sales: "it just feels like these cyanograph (...) films are a quick cash grab" (Twitter, 2014). Doubters also alerted Impossible to what it could lose through sales, publicity and technical support if it did not make them feel more valued: "We made it possible. The way you're going, a lot (...) will walk away" (Twitter, 2013).

\section{Case Overview at End of Phase 1}

From April 2013 until December 2014, Impossible rapidly transformed itself to focus on creating the future of analog by targeting mass-market, lifestyle customers. The venture had thoroughly changed with respect to its identity and strategy. An executive observed that the venture was "gradually pulling everything under the sway of one vision" (\#44). The CEO who had led the pivot to this point declared his task complete internally and stepped down in December 2014. His successor thanked him “for everything he's done in the past year and a half for Impossible" and gratefully noted that he had "transformed a beautiful but unsustainable dream into a company with a future" (Impossible Blog, 2014b). The new CEO 
was intent on continuing the pivot and the pursuit of new, mass-market audiences to ensure the venture's long-term viability.

At the same time, there were deep concerns within Impossible about the reactions of its user community and the new CEO realized that the venture faced a serious strategic predicament. Indeed, as community members were an important stakeholder group, their negative reaction jeopardized the venture's pivot: those involved said relationships were "getting really nasty" (\#4) with "thousands of tweets in anger" (\#9) as Impossible’s "trust with the community (...) [was] broken" (\#53). They voiced these views stridently across multiple communication channels - online and offline - through unvarnished comments such as "I hate Impossible", which deterred coveted new customers. An employee explained: "If the experts are saying that the product is really bad, then they [new audiences] are not gonna buy into it” (\#50). Community members also boycotted Impossible film, jeopardizing the venture's sales, and stopped sharing their expertise with the venture, thus impeding the venture's product development.

\section{Phase 2: Tackling the Identification Crisis}

The hostile reactions from members of the community posed a major strategic challenge for Impossible. Faced with this challenge, the venture sought to rebuild its relationships with them through strategic actions that we term identification reset work. This involved emotionally reconnecting with stakeholders to put their relationship on a new basis. We identified two distinct types of identification reset work (seeking empathy and mythologizing) that Impossible enacted to address the challenges that it encountered from its community. The venture was not always fully aware that it faced opposition from two discrete groups (attackers and doubters). As a result, it initially directed its identification reset work at the community as a whole. Interestingly, however, different types of identification reset work resonated more or less with attackers and doubters, and as a result Impossible started to realize that the resistance it faced was not homogenous. Over time, this dynamic 
allowed Impossible to engage in a more fine-grained targeting of attackers, who often were especially vocal. In this section, we begin by looking at the identification reset work enacted by Impossible that especially resonated with attackers, and their reactions to it. We then turn to the identification reset work that particularly resonated with doubters, and their reactions to it.

\section{The Attackers}

The first type of identification reset work that Impossible employed involved seeking empathy for the challenges it faced (see top box in center of Figure 3). This resonated particularly strongly with attackers: it prompted many of them to stop confronting Impossible and instead to disengage from the venture, although a small group remained attackers. We first outline this type of identification reset work and then show attackers' two distinct reactions to it.

Identification reset work: Seek empathy for venture challenges. Confronted with such hostile opposition, Impossible sought to convince community members of the difficulty of its situation in an effort to generate empathy for the commercial and technical challenges that it faced. Impossible staff sensed that many community members perceived that the venture had betrayed the community to which these members felt such a strong attachment. This seemed to preclude them from changing their view of the venture. Impossible wanted to shift the focus of these members from a narrow concern with their perceived betrayal, to the venture's broader challenges in keeping the technology and company alive. While the venture continued its efforts to attract new consumers, especially among fashion and lifestyle audiences, staff realized the "need to build an element of this empathy" with its user community (\#74). An employee involved in these efforts detailed the approach:

"We are all struggling, we are all learning, changing, growing as human beings. I think what was very important for me was that the community realized that for every one photo that they took that didn't work, we were (...) testing literally hundreds of different batches of chemistry. (...) We were a small start-up in Berlin with a small team of creative people who were just trying to do something beautiful for the world. 
(...) we were struggling and they were struggling, but if we were all in it together and we were (...) then it was a little less difficult to swallow" (\#53) [.]

As this passage shows, Impossible exposed its major struggles to convince stakeholders that necessity and good intentions drove its actions. Its efforts to seek empathy for its challenges involved: stress technical struggles and remind about mortal threat.

In stressing the technical struggles that it faced, Impossible sought to convey the complexity of film production and the regular setbacks it experienced; the intention was to convince community members that they should not take the film for granted.

Impossible sought empathy with community members both proactively and in response to specific criticism. For example, Impossible launched a clip about its journey, emphasizing that it had "no clear path to follow and many obstacles to overcome", while asking rhetorically about its challenges: "But how is the Impossible possible?" (Impossible Youtube Channel, 2015a). From 2014 onwards, the venture increasingly let its technical team, and especially its new Chief Technology Officer (CTO), front public efforts to explain Impossible's plight, often through live chats on Twitter. For example, when faced with the attack "Impossible weasles when they say certain chemicals aren't "available.", Impossible tweeted back:

"[CTO] Stephen Herchen worked alongside [Polaroid founder] Land. He doesn't 'weasel'. Ever. The chemical challenges his team faces are significant. (...) we cannot make you believe. We can just do our very best to improve our films" (Twitter, 2014).

Impossible also issued regular reminders about the mortal threat that it was facing.

During fieldwork an employee explained how frustrated he was that community members:

"often only judge Impossible from their specific and narrow situation without understanding the context. It is important to broaden their perspective by explaining the very difficult situation that Impossible finds itself in" (Fieldnotes).

More broadly, Impossible regularly responded to hostile tweets by invoking its fight for survival. In one instance Impossible faced a hostile community member who attacked it with the tweet "focus on the film \& forget the User. Sounds like a great plan!!!" (Twitter, 
2013). In this interaction, Impossible sought to elicit understanding for its precarious situation: "We are fighting to save the company AND make the film better" (Twitter, 2013). Impossible also proactively stressed that it faced a clear and present danger, such as in this blog post: "our production costs are very high and our margins are currently not sufficient to cover all of our fixed costs" (Impossible Blog, 2014c).

Attackers responded to Impossible's identification reset work in two ways. A core group was appeased: this group reconsidered its relationship with Impossible. Although none of them resumed their support for the venture, they disengaged from it and ceased their overt hostility. A second group - very much in the minority - remained attackers and continued to be hostile to the venture. We now explore these reactions (see ovals in top-right of Figure 3).

Attacker reaction (1): Disengage from venture. The core of the attackers responded to Impossible's efforts to seek empathy for its challenges by shifting their focus away from their individual situation and feelings of being wronged by a duplicitous venture, and instead began to acknowledge the broader challenges faced by Impossible in its efforts for analog instant photography. As a result, these attackers stopped confronting the venture. However, they did not start supporting it again; rather, they disengaged from Impossible. In other words, they deidentifed, no longer experiencing "a close tie to this company in any way, whether good or bad" (\#24). This transition from attacking to disengaging from the venture consisted of two elements: respect efforts for film, and make peace with change and exit.

Jack is one of those who disengaged from Impossible after having initially opposed the venture due to its pivot. He works in the creative industries and backed Impossible earlyon when "the community was really active on Flickr (...) [we] $\operatorname{tr}[$ ied] to get the word out about Impossible" (\#24). He was shocked about the pivot as he believed that "[Impossible] didn't really care about the people, the photographers who sort of backed them from the beginning" (\#24). Jack observed that "it's always harder to lose something you had than to 
not have it at all" (\#24). However, he later disengaged from Impossible when he came to accept the genuineness of Impossible's struggles: 'it did seem like they couldn't get rid of problems (...) [now] it's getting better, for sure" (\#24). This led him to switch his focus to the venture's products, rather than questioning Impossible's motives: He explained his reasoning:

"am I more concerned about how I feel about them and how they come off as if they were a person? Or am I willing to let that go because [of] the product that they put out" (\#24)[?]

This calmed his anger at losing his close relationship with Impossible and he "completely lost interest in them" (\#24). Attackers like Jack disengaged from the venture in response to its efforts to elicit empathy for its situation because they came to accept that the venture was in a precarious strategic position. For example, one community member who had "felt betrayed" (\#6) and approached Impossible through this personal and narrow lens, changed his focus as Impossible exposed its many challenges:

'I've always appreciated what The Impossible Project has done because it's a monumental undertaking and they have made continuous and regular improvements to the quality of the product" (\#6).

As this quote illustrates, accepting the venture's genuineness was often linked to respecting the venture's efforts for its film despite its struggles. Similarly, when an Impossible employee explained another set of challenges: "Release process - matching negative, sheet \& developer for good sensitometry. Very challenging!”, an attacker empathized with the venture's difficult situation: "appreciate the hard work" (Twitter, 2015). Another attacker concluded: "what's the most common is (...) a shift from "oh I hate them" to "well I guess you're not that bad and I'm going to shoot them [Impossible film] when I feel like it" (\#23). Thus when learning about Impossible's struggles, many attackers reassessed their view of its pivot: rather than alleging that the venture was betraying them for sinister reasons or because it did not care, they accepted that the venture had been forced to take difficult decisions.

Attackers who disengaged made their peace with Impossible and exited. One 
explained that he no longer wished that "Impossible goes down in flames (...) It wouldn't have been my sentiment two years ago when I was (...) definitely angrier" (\#24). Once they disengaged, this group usually bought little - if any - film, as one informant explained: "I haven't shot Impossible in almost a year" (Twitter, 2015). Consequently, they did not buy large amounts of Impossible film, as they had done in the past. Crucially, however, this group no longer participated in attacks designed to impede Impossible's pivot.

Attacker reaction (2): Continue to attack venture. A small group of attackers ignored Impossible's identification reset work and continued their opposition. As an Impossible employee explained: "You know, we tried, we can't win everybody (...) Of course there were still a few people who just never let it go and they were like, "No, I made my decision" (\#53). These attackers continued to focus on Impossible's perceived betrayal of the community and did not stop fighting the venture.

Jill, a designer, is a former community member who continued to oppose Impossible:

"There was a sense that "we" were all in this together. (...) all that has changed completely [with the pivot]. (...) They've expressed a clear disregard for anyone who might be shooting instant film for nostalgia purpose[s], and are instead very focused on a hip, cool image" (\#33).

She persisted in viewing Impossible through the prism of betrayal because "they damaged the Impossible community beyond repair", which was "heartbreaking” (\#33).

Other attackers also remained focused on what they saw as Impossible's betrayal of the community because they continued to question the venture's genuineness. One claimed that the venture continued to show "greediness and vanity" since it "became shitty with [the] community", questioning whether it genuinely cared about analog film or just about money (\#34). Attackers also continued fighting Impossible by denouncing its products on social media. For example, when a user uploaded pictures of a faulty pack of new film, an attacker tweeted sarcastically: "great work!” (Twitter, 2015). Similarly, when Impossible launched an analog-digital crossover camera in 2016, an attacker tweeted: "how brilliant a joke it was" 
(Twitter, 2016), while another called the camera "ugly and useless" (\#34).

\section{The Doubters}

We now turn to consider the second type of identification reset work that Impossible employed - mythologizing - and the reactions of doubters, with whom it particularly resonated. This type of identification reset work consisted of two aspects: (1) mythologizing the technology (i.e., analog photography vis-à-vis digital photography) and (2) mythologizing the venture's commitment to the product (i.e., the specific films it was developing and offering). Mythologizing involved passionately idealizing these two issues to highlight the importance and sheer scale of the venture's struggles, as well as its efforts to overcome them. This prompted doubters to disengage from Impossible or to resume their support for it. Notably, none of the doubters in our data set became attackers. We first consider the identification reset work based on mythologizing (see bottom box at center of Figure 3), followed by doubters' reactions to it.

Identification reset work: Mythologize the technology. A key approach that Impossible employed to respond to the identification threats of its doubters was to celebrate the overarching technology; i.e., the medium of analog instant photography. Specifically, by revering the technology, the venture would be able to show how important its efforts were, thus helping to idealize its struggles. Impossible's efforts to mythologize the technology were based on two elements: link to technology's origins and celebrate analog in digital world.

Impossible linked itself to the technology's celebrated Polaroid origins and eulogized these in various ways. This involved regular posts across communication channels, including Twitter, the venture's blog and its newsletters, to highlight important aspects of the heritage of Polaroid photography and connect the venture to these. For example, Impossible released a clip in which its CTO Stephen Herchen shared his excitement about the history of analog instant photography and Impossible's role in keeping the "magic" alive: 
"If you go back to (...) Dr. Land who was the inventor of instant photography, one of his visions was to take this most chemically complicated product and hide all this complexity from the user. Have the picture come out and just let them marvel at it, let them enjoy it (...) and that is the magic" (Impossible Youtube Channel, 2015b).

On another occasion, Impossible linked itself to Polaroid's legendary founder Dr. Edwin Land by retweeting the following: "Happy Birthday, Dr. Land! Thanks for such a wonderful invention \& thnx @ Impossible_HQ for creating beautiful films”(Twitter, 2014)!

In addition to linking itself to the technology's origins, Impossible also celebrated the role of analog photography in a digital world, extolling its virtues and continued relevance despite the increasing dominance of digital technology. The venture drew on a variety of communication channels, such as Twitter and its blog, to do so. Specifically, Impossible highlighted the distinctive features of analog photography and the unique experiences it offered users. For example, in a blog post the venture celebrated "the analogue revolution in our digital age (...) [which provides] physical, tactile and meaningful means of expression in a predominantly tech-driven world" (Impossible Blog, 2014d). On another occasion, the venture emphasized the importance of the tangible aspect of analog photography, commenting in a tweet: "You have a real picture, it's not just a digital file" (Twitter, 2015). Thus, through these efforts, Impossible established the significance of its struggles for the technology, focusing on analog instant photography's distinctive and evermore rare features.

\section{Identification reset work: Mythologize commitment to product. In addition to} mythologizing the overall technology, Impossible also mythologized its commitment to the specific products that it was developing. While the former celebrated the medium of analog photography to show the importance of Impossible's efforts, the latter focused on glorifying the venture's commitment to improving the instant films that it produced despite the struggles it faced. This second aspect of mythologizing was based on three elements: stress devotion to product, show progress in tackling struggles, and enlist credible supporters.

First, Impossible publicly stressed its devotion to the product by emphasizing its 
passion for improving its films. This approach sought to show that Impossible was committed to the film, rather than being primarily driven by financial motives. For example, in an interview with a photography publication, CTO Stephen Herchen highlighted his devotion to the product "is driven through passion. 'I love what The Impossible Project is trying to do (...)"' (James, 2016). Similarly, when responding to a community member on Twitter, Impossible stressed its devotion to improving the film: "to be clear this is a real team effort. a small but passionate team" (Twitter, 2015). Relatedly, the venture regularly affirmed its devotion to its films despite the challenges it faced, such as in this newsletter when its CEO stressed: "we're not taking this job lightly, even for a second" (Impossible Newsletter, 2015). Impossible also proactively showed its progress in tackling the struggles it faced. This involved regular messages in which the venture extolled how it had overcome key obstacles and improved the film as a result, such as in this message:

"It's been more difficult than anyone could have imagined to get even this far, but we have no intention of giving up (...) we're going to release a new Pioneer batch of what will one day become the Color Gen 2.0. Early results have blown us away over here, and I'm hoping you will feel the same way" (Impossible Newsletter, 2015).

Similarly, in a magazine article Impossible described the hard-earned improvements to its film, emphasizing the complexity of the chemistry and the difficulties that this presented:

"Instant analog film might just be the world's most chemically complex entirely manmade product ever created. Numerous chemical reactions take place (...) Controlling all of this is our challenge. (...) [W]e have recently made a change (...) that enables the initial image to be seen much faster" (Impossible Magazine, 2015).

An employee summarized the community's reaction to the venture's efforts to show its progress with the struggles it faced as follows: "It was really exciting to see the community responding to the $\mathrm{R} \& \mathrm{D}$ efforts that we were making because obviously all of the effort was just going into making the films better" (\#53).

Impossible also enlisted credible supporters to mythologize its commitment to the product and attest to its efforts to overcome these. In doing so, it sought the support of key 
community members who could publicly back Impossible and convince others to do likewise.

To gain credible supporters, Impossible offered key community members extensive information about film development and gave them privileged access to the venture. This included giving them film ahead of its official launch and hosting them at its offices. Impossible also provided technical explanations and background details about products, problems and future releases. One executive stressed the importance of offering:

"information to them first and (...) stuff that they would be interested in, like technical details. (...) people do listen to them because they are experts. (...) It's all about (...) making them feel like they know something that no one else gets" (\#50).

For example, on one occasion Impossible told a photo blog run by community members how it came to face significant challenges in the development of one of its films, and described its spirited efforts to overcome these challenges. The photo blog responded by thanking Impossible for "giving us this update on the status of B\&W spectra film and look forward to seeing this project back on track soon!" while blog followers enthused: "It's great when companies are this transparent" (Pdexposures, 2014b). In this instance, Impossible took up the offer by the bloggers to share technical details about film progress with the community.

In response to Impossible's identification reset work, doubters reconsidered their relationship with Impossible: they either disengaged from the venture or resumed support for it (but notably nobody in our sample became an attacker). We now explore these two reactions (see ovals at bottom-right of Figure 3).

Doubter reaction (1): Disengage from venture. A first core group of doubters chose to disengage from the venture in response to its identification reset work. As a result, they no longer cared about the venture and avoided it. Disengaging from the venture consisted of two main elements: respect efforts for film and make peace with change and exit.

Ricky is a designer who switched from doubting the venture to disengaging from it. He had supported Impossible from the start because he liked "contributing to the growth of 
this product that they were making" (\#23). He was surprised by the pivot and by the venture's move away from focusing on the technical needs of its user community: "it's very mass market (...) [a]nd that alienated the people who use it for more of a fine art medium, and (...) who had been with them for so long before that" (\#23).

He shared the concerns of many others about Impossible's move towards digital technology and its reduced focus on the film types that its core community wanted. However, in response to Impossible's efforts to mythologize the technology and its commitment to the product, Ricky reconsidered his view and acknowledged the venture's need to change: "I don't know how long they'd be able to survive in the community and [with] the fine art aspect” (\#23). Despite his unhappiness about how Impossible had changed, he showed respect for Impossible's efforts for its film: "looking at it now the focus on the more technical aspect does make some sense" (\#23). This enabled him to disengage from the venture: "I myself haven't shot Impossible [film] in a while" (\#23).

Thus those who disengaged came to respect the venture's efforts for its film. They no longer questioned whether Impossible was devoted to analog instant film. For example, one community member observed Impossible's commitment to the film and praised its efforts to improve it: "I was actually impressed with how much progress they made", echoing Impossible's message that it had achieved much despite facing significant struggles (\#55). Another community member praised that " $[\mathrm{t}]$ hey have actually come up with a really nice product, just by tinkering with it" (\#10). He emphasized that they are "committed to the products" and that "they have really worked hard" (\#10), thus echoing key themes from Impossible's mythologizing efforts. As this quote shows, doubters' respect for the venture's efforts for its film was at times connected to accepting the venture's genuineness. This group came to recognize that Impossible was committed to the film and no longer saw the pivot as a sign that the venture was disingenuous in its efforts for analog instant photography. 
Doubters became reconciled with the change: they came to terms with it and exited. One informant explained that he and others had "made their peace with it and realized that's how it is (...) I still look back at those good times, but I don't know how long that would have been able to last or keep the company afloat” (\#23). Individuals in this group stressed that they had no relationship with Impossible anymore and rarely bought its film. They adopted a pragmatic, detached stance that was primarily based on indifference - "they're [Impossible] still around (...) If I want to shoot it [their film] I can” (\#23) - to a stance based on outright avoidance - "I've stopped using Impossible film altogether" (\#7). These individuals neither turned against Impossible nor supported it.

Doubter reaction (2): Resume support for venture. A second core group of doubters resumed their support in response to Impossible's identification reset work. They responded to Impossible's mythologizing by reconnecting with the venture on the basis of reverence for its products and its efforts to improve them - reverence being an emotion that can act as a powerful motivator (Massa et al, 2017). In other words, this group reidentified with Impossible. This reaction stands in contrast to those doubters who disengaged from the venture in response to Impossible's identification reset work - a group that came to respect the venture's efforts without developing reverence for Impossible or its films, as discussed above. Resuming support for the venture consisted of two elements: feel reverence for film progress, and understand challenges and defend venture.

Robert is one of those who doubted the pivot but came to support the venture subsequently. He is an entrepreneur who initially identified with Impossible because he felt that the venture was focused on photographers like him: "I have been with Impossible for a really long time. (...) they did really well with reaching out to the photographers" (\#4). However, he was alarmed about Impossible's pivot and vented his concern on Twitter:

"I woke up one Saturday (...) [to] this sort of battle with Impossible because they tweeted about all the changes that they were going to make. (...) Impossible definitely 
saw how nasty we can be" (\#4).

Despite having felt unsettled about Impossible's pivot, Robert came to terms with it as he began to again admire Impossible's passion for analog instant photography and its efforts for creating great film despite its struggles. In one instance he responded to an announcement in which Impossible announced an improved film by noting how much support Impossible deserves for its efforts. Similarly, he regularly tweeted that he was excited when Impossible launched new products. Like many supporters, he returned to shooting large amounts of film - "about 40-50 packs of Impossible film a year" (\#4) - and was proud of buying the venture's new flagship analog-digital crossover camera in 2016. Robert resumed publicly supporting Impossible and once again spent hundreds of dollars on its film and hardware.

Feeling reverence for film progress - and focusing their interactions with Impossible on this - led doubters like Robert to become supporters again. For example, one supporter explained: "The fact that they are nearly at the stage where it takes 10 minutes [for a picture to develop], that's amazing within a space of a few years" (\#13). Another supporter similarly voiced profound appreciation for the improvements that Impossible made to its film: "I have the utmost respect for what they are doing" (\#3). Similarly, after a live Twitter Q\&A session with Impossible's R\&D team, a supporter tweeted: "thanks stephen \& win for the insights (...) and a big thank you to the whole factory team" (Twitter, 2015).

Those who supported the venture came to understand the challenges that it faced and defended Impossible with displays of admiration. They once again identified with the venture and celebrated it for persevering despite the significant struggles that Impossible had faced. One supporter stressed:

"I am proud to be associated with them. (...) I deeply appreciate that they (...) have worked their butts off to get this company viable. I mean, nobody else tried to do that. And for all the criticism they receive, they should realize that there are people out there who know what they went through. (...) I'm deeply grateful to them" (\#25)[.] 
Community members often switched from doubter to supporter due to personal contact with credible peers who vouched for Impossible's significant efforts for the product. As one supporter with a friend at Impossible's Berlin office explained: "I have a good friend in Berlin (...) after a few months of (...) restructuring, they are on a good path. (...) I am really looking forward to shooting this stuff" (\#19). A blog run by community members typified the understanding shown by many former doubters for Impossible's struggles and their renewed reverence for the venture: "We all know the struggles they had for sure, but they were successful. (...) Long live instant film and thank you Impossible” (Snapitseeit, 2014). Supporters once again bought much film and resumed their backing for the venture.

\section{Case Overview at End of Phase 2}

At the end of our case in 2016, a major part of the original user community supported or tolerated Impossible once again, while only a small group opposed it. The venture had continued executing its pivot and pursuing new audience groups throughout, while at the same time engaging in identification reset work to repair relations with its community members - a difficult balancing act to perform. Impossible employees observed that the venture's efforts to tackle the identification challenges of these stakeholders "seemed to help for most people" (\#53) and helped to render the pivot a success: "that's a great thing that we accomplished, to grow (...) [and] keep this community around" (\#52). While many of the original community members "might still believe to some extent that it wasn't what it used to be, they are perfectly okay moving forward" (\#48)[.] Impossible employees were excited that they had been able to "transition from this very niche, indie kind of project (...) [into] a brand (...) that didn't alienate the community but also allowed new people to feel that they could come” (\#53)[.] Impossible's CEO shared his satisfaction at the venture's stabilized situation:

"It was much costlier to get here than we thought and took much more time. Time is money. We are now getting to a point at which everything becomes profitable. (...) Those in their mid-20s and mid-30s buy our products the most" (Zollner, 2016:1). 
This concludes our investigation of how pivots affect stakeholders' identification relationships with new ventures and how these ventures can tackle the resulting challenges.

\section{Epilogue}

By May 2016, Impossible had successfully completed its pivot and launched its new analog-digital crossover camera "I-1" (Sax, 2016). In September of the following year, Impossible took the opportunity to rebrand as Polaroid Originals and launched a new camera: the "OneStep+", which allows users to edit photos in an app (Sinibaldi \& Stone, 2018). Thus, the venture continued the strategy on which it first embarked during its pivot: making analog instant photography more widely accessible by engaging with the digital world.

\section{DISCUSSION}

We set out to explore the puzzle of how new ventures can manage relationships with stakeholders who initially identify with them but then turn against them as they pivot. To do so, we conducted a qualitative process study of Impossible, an analog-only, niche producer of instant film that pivoted into an analog-digital, mass-market photography firm. Impossible relied on its user community for resources, but the new direction threatened community members' identification with the venture. Based on this case, we offer a process model of stakeholder identification management during new venture pivoting. We find that ventures can reconnect with many hostile stakeholders during pivots by engaging in identification reset work. Our paper contributes to research by theorizing identification management in new ventures, user community identification, and new venture pivoting.

\section{Identification Management in New Ventures: The Role of Identification Reset Work}

Our main contribution is to show how new ventures manage relationships with key stakeholders whose identification with the venture is threatened. To do so, we developed a process model of stakeholder identification management (see Figure 3). Underpinning our model is the concept of identification reset work. Core to identification reset work are two strategies that ventures can enact when relations with stakeholders who originally identified 
with them break down: 1) seeking empathy for the venture's challenges, and 2)

mythologizing the technology and the venture's commitment to its products. The crux of our argument is that, through these forms of identification reset work, new ventures can overcome much of the affective hostility expressed by their stakeholders by exposing the venture's struggles and its efforts to overcome them. In doing so, the venture shows the purity of its motives and the painful challenges that have 'forced' it to deviate from them, thus creating a shared emotional narrative with stakeholders. This can overcome the highly damaging narrative of "us versus them" that tends to pervade stakeholder relationships that turn sour. Intriguingly, the venture's weaknesses thus become transformed - at least temporarily - into strengths that help it to ameliorate negative stakeholder emotions by invoking a set of struggles that are experienced both by the venture and its stakeholders. In our case, community members largely - albeit not fully - ceased their hostility in response to Impossible's identification reset work that revealed the painful financial and technical challenges that it was seeking to overcome. Specifically, Impossible sought empathy by divulging details of its financial and technical problems. Relatedly, by mythologizing the technology and its commitment to its products the venture showed the importance and sheer scale of its struggles in keeping analog instant photography alive in a digital world. The insight that revealing weaknesses - which, on the face of it, place ventures in a negative light - can have positive effects on stakeholder identification may seem counterintuitive. However, it is supported by authenticity scholars who find that exposing "uncommon" organizational elements helps convince audiences of the genuineness of an organization's claims (Carroll \& Wheaton, 2009).

Taking a step back, our interpretation of the events in our case is that Impossible's user community reacted so strongly to the change of direction because community members anthropomorphized the venture - attributed human qualities to it (Ashforth, Schinoff, \& 
Brickson, forthcoming). In other words, they saw Impossible as a fellow member of the analog instant community or even as a friend. Community members were dismayed by the pivot because, from their perspective, it revealed the venture as coldhearted - even callous. This presented Impossible with a major dilemma because research shows that organizations struggle to pacify stakeholders once they turn hostile, especially when their emotions become “all-consuming, paralyzing” (Dukerich, Kramer, \& Parks, 1998:250; Elsbach \& Bhattacharya, 2001; Fiol, Pratt, \& O’Connor, 2009).

Through its display of apparent weakness in the face of fierce criticism, Impossible responded in a way that was highly resonant to the community because the venture revealed a sense of vulnerability that strikes at the heart of what it means to be human. A particular advantage of the identification reset work that Impossible enacted was that it enabled the venture to rebuild a connection with many of its stakeholders by fostering reverence for its efforts, while at the same time placing the relationship on a more distant footing. Specifically, Impossible showed that it was united with its stakeholders in shared struggles for analog photography and instant film, but at the same time it did not give the impression that it was a "close friend" to them. Mythologizing is particularly helpful for achieving this: it allows ventures to showcase and elevate their unceasing commitment to issues that are important to stakeholders, without giving them the impression of a deeply personal relationship and tying the venture into an associated set of obligations. We think that a tendency for anthropomorphism is likely to be a distinguishing feature of the identification dynamics of entrepreneurship. This is because new ventures often build closer connections with external stakeholders than more bureaucratic, mature firms.

These arguments about identification management are novel: while an emerging body of research has shed important light on the management of identification in established organizations (Ashforth et al., 2008; Besharov, 2014; Petriglieri, 2015), processes of 
identification management in new ventures have not been systematically examined. Yet, as our study of Impossible reveals, new ventures face different identification challenges and the insights offered by existing work do not appear to be directly applicable. The main reason is that identification research on established organizations has focused on the management of employee identification - stakeholders who are internal to the firm. By contrast, studying identification in the context of new ventures brings to the fore the crucial role of external stakeholders such as user communities. Our study shows very clearly that identification management in this context is distinct.

Specifically, existing research on identification management has highlighted two main strategies that established organizations can adopt to repair relations with employees whose identification is threatened. First, organizations can communicate their strengths and emphasize positive organizational attributes (Besharov, 2014; Pratt, 2000). Second, organizations can encourage stakeholders to enact core aspects of the organization's identity (Besharov, 2014; Fiol, 2002; Petriglieri, 2015). The concept of identification reset work that we uncover stands in stark contrast to these studies, not only because it is enacted by new ventures and focused on external stakeholders, but because it is predicated on the idea that invoking shared struggles - rather than emphasizing positive organizational attributes - can help rebuild troubled relationships.

We believe that the insights we offer are important, not only because they extend the organizational identification perspective to new ventures, but also because doing so deepens our understanding of entrepreneurship from an organization theory standpoint. Research in this space has coalesced around the concept of legitimacy and is focused on how ventures gain the baseline acceptance from society that they need to operate (Aldrich \& Fiol, 1994; Fisher et al., 2016; Suchman, 1995). However, the micro-interactions between ventures and their stakeholders tend not to be explicitly examined. Yet new ventures often 
disproportionally rely on "special" relationships with specific stakeholder groups (Lakhani \& Kanji, 2008; Weber et al., 2008). New venture legitimacy is necessary - but insufficient - for these key relationships, because ventures also require stakeholders to identify with them. Identification scholarship can offer important insights that help explain how ventures navigate these situations, thus complementing legitimacy research.

Relatedly, and while not our explicit focus, our study potentially connects to research on discursive legitimation. Specifically, mythologizing could be conceptualized as a discursive legitimation strategy, as well as a type of identification reset work (Suddaby \& Greenwood, 2005; Vaara \& Tienari, 2010). At its core, mythologizing is an emotional appeal to stakeholders designed to portray the venture as exceptional. While, in our case, it was used to reconnect stakeholders who were skeptical about the venture's new direction, it could equally be used to build legitimacy by convincing stakeholders that the venture has the requisite ability and motivation to deal with the challenges that lie ahead of it. Such an approach could complement the discursive legitimation strategies identified in the existing literature, such as normalization and moralization (Vaara, Tienari, \& Laurila, 2006).

\section{The Dark Side of User Community Identification}

There is growing interest in the role of user communities and a recognition that they represent a particularly important kind of stakeholder who can be uniquely supportive of organizations (Harrison \& Corley, 2011; Von Hippel, 2001; Weber et al., 2008). They may play an especially significant role for new ventures, whose resource constraints underpin a "liability of newness" (Stinchcombe, 1965) that often renders their early years precarious. However, while we acknowledge the positive role that user communities can play, our study also explores a dangerous dark side associated with this type of stakeholder: as the case of Impossible shows, user communities can turn quickly from staunch allies with strong affective ties to new ventures, to ruthless enemies motivated by a sense of betrayal - a radical 
switch that has not been an explicit focus of the literature. Thus, we show that the fervor of user communities can be a double-edged sword.

Interestingly, this finding is not easily explained by the existing literature on organizational identification. Specifically, scholars have argued convincingly that positive emotions towards an organization can act as a buffer when stakeholders experience identification threats (Eury et al., 2018; Kreiner \& Ashforth, 2004). Similarly, stakeholder theorists have assumed that positive emotions support stakeholder relationships in difficult times (Laplume, Sonpar, \& Litz, 2008). By contrast, we find that strong positive emotions on the part of user communities can pose a danger to new ventures. A possible explanation for this discrepancy concerns the small scale of new ventures such as Impossible. Specifically, large-scale organizations tend to be characterized by multiple elements and activities. Thus, while stakeholders may disidentify with one part, this may be offset by feelings of support for another part; i.e., they may develop a "split identification" (Gutierrez et al., 2010). However, new ventures' user communities tend to identify with core venture attributes and identification threats are therefore more likely to be linked to the whole organization rather than to discrete or peripheral parts. In these situations, positive emotions may not serve as a buffer but rather as a boomerang. Thus, instead of having a calming effect, the initial presence of intense positive emotions amplifies the sense of betrayal - a strong negative response akin to that exhibited by stakeholders after venture failure (Mantere, Aula, Schildt, \& Vaara, 2013). While this insight is tentative, we do think that it augments our assertion that the identification dynamics of new ventures are distinct.

The risk that the fervor of user communities can work against ventures in times of change makes it particularly important for new ventures to understand the precise nature of the identification dynamics at play. Interestingly, we delineate two distinct foundations through which members of user communities can identify with a new venture. First, members 
may identify on the basis of a sense of belonging to the community itself; i.e., they connect with the venture through the solidarity that emerges from interacting with other users who belong to the community (Rossner \& Meher, 2014). Second, they may identify on the basis of the venture's products or technology; i.e., they value and gain satisfaction from key functional or symbolic attributes of the venture's product offering (Harrison \& Corley, 2011; Von Hippel, 2001). Both types of identification lead members of user communities to support the venture extensively. However, as indicated in our model, not only does each type lead community members to value different aspects of the venture, it also leads them to respond in different ways when their identification is threatened, and requires different forms of identification reset work to repair relationships.

Contestation by stakeholders, such as user communities, is likely to become more common as people become more active online (Harrison \& Corley, 2011; Massa, 2017). Digital platforms make it easier for individuals to engage in coordinated "resistance work" and to attack organizations with which they disagree (Massa, 2016). For new ventures, the implications are profound: rather than embracing the seemingly "free" support offered by passionate user communities, new ventures need to carefully select their supporters, and to avoid bringing them too close, so that they can temper the risk of a dangerous backlash.

\section{The Process of New Venture Pivoting}

For many years, the dominant approach to entrepreneurship practice was the "business planning paradigm" (Honig, 2004): starting with a clearly thought-out blueprint for a venture, amassing significant upfront investment, and then executing it accordingly. This approach has been increasingly questioned, however, particularly for ventures in dynamic environments where plans can be obsolete by the time of product launch (Blank, 2013).

In its place, a new paradigm has emerged - the so-called "lean startup" methodology - an approach to entrepreneurship that emphasizes experimentation through the continuous testing of new ideas and rapid responses to changing competitive threats or consumer 
preferences (Ries, 2011). Pivoting is a key component of this new paradigm and has become extraordinarily influential - embraced by incubator, accelerator and business school programs around the world (Klebahn \& O'Connor, 2011; Nobel, 2011; Ries, 2011).

However, while pivoting has undoubtedly become a core strategic practice for many new ventures, it has not been extensively theorized. An important exception is Grimes (2018), who examined the process of "creative revision" enacted by entrepreneurs as they pivot to a new venture idea. He finds that entrepreneurs have to overcome identity-based resistance to pivoting as their original idea is closely intertwined with their sense of self. Crucially, Grimes focuses on very early stage entrepreneurs - that are "pre-revenue, precapital investment" - when the venture primarily exists as an idea in the entrepreneur's mind.

Our study suggests that it is important to distinguish this type of early stage pivoting with pivots that happen in later stage ventures - such as in our case - once a new venture has embarked on a particular strategic path for a sustained period. We label the early stage pivots that Grimes studied as "conceptual pivoting" and the later stage pivots that we study as "live pivoting". This distinction is important because our analysis indicates that the dynamics underpinning each of them are very different. Specifically, our case shows that the key challenge facing ventures engaged in a live pivot does not relate to internal identity dynamics - Impossible transitioned its identity in a fairly straightforward fashion through the pivot that we observed. Rather, as ventures rely strongly on external resources at this stage, they face the key challenge of managing relationships with resource providers who may be shocked by the venture's radical shift. Entrepreneurs engaged in (early stage) conceptual pivoting are unlikely to face this issue as their relationships with stakeholders are usually nascent. We therefore identify a major potential hazard inherent in pivoting for later stage new ventures that rely on external stakeholders. Crucially, we show that pivoting in this situation is far from a 'cost free' strategic option, as is often portrayed in the emerging literature. 


\section{Limitations and Future Research Opportunities}

Our study has limitations which offer possibilities for future research. First, we explored how a new venture's key community reacted to its pivot but did not investigate the internal dynamics of the community. We encourage scholars to explore how these internal dynamics work, how competitors can seek to influence them, and how focal firms can react.

Further, it is likely that the timing of the pivot in our case influenced the dynamics observed. Specifically, the pivot happened when stakeholder concern for the survival of instant film was at its peak, which could have heightened stakeholder emotions. Moreover, the mere passage of time - as well as the identification work of Impossible - may have been a factor in the mellowing of stakeholder reactions. Given recent progress in explaining how organizations use time strategically (e.g., Kunisch et al., 2017), it would be intriguing to explore how new ventures deploy temporal work to defuse identification threats.

Moreover, our case reveals the problems that can arise for ventures when stakeholders anthropomorphize them. At the same time, it is clear that new ventures can also gain significant resources from stakeholders who do so (Ashforth et al., forthcoming). This presents ventures with an intriguing tension that has not been examined in the literature. It would be interesting to explore how new ventures can harness the positive effects of anthropomorphism while simultaneously mitigating the negative ones.

In addition, our study explores a case in which a venture's pivot triggered a core stakeholder group to evaluate the venture in an overwhelmingly negative manner. However, new ventures often face polarized emotional reactions - simultaneous displays of positive and negative emotions - from stakeholders. This may be so extreme that some stakeholder stigmatize these ventures (e.g., Hampel \& Tracey, 2017; Helms \& Patterson, 2014), while others celebrate them (e.g., Harrison \& Corley, 2011; Massa et al., 2017). For example, ridesharing platform Uber often provokes a "love it or hate it" response, with campaigns that argue for or against it (Atkins, 2016:1). It would be interesting to study how new ventures 
that face polarized affective stakeholder reactions manage identification dynamics in this challenging situation. An intriguing puzzle is how new ventures deploy arguments based on pathos - emotion-based appeals - when they face audiences that display polarized emotional states (Erkama \& Vaara, 2010; van Werven, Bouwmeester, \& Cornelissen, 2015).

Finally, we identified two negative stakeholder reactions (doubting and attacking). In our specific case, the venture was able to overcome much of the affective hostility that it faced through its identification reset work. However, it is important to acknowledge that ventures may face other types of hostile reactions from stakeholders, and that these reactions may vary in their intensity. We believe that both forms of identification reset work that we identified - seeking empathy and mythologizing - are likely to be effective in addressing a range of negative stakeholder reactions, but would encourage additional research which explored this question further.

\section{CONCLUSION}

New ventures often change profoundly in their early years - pivoting in order to find a sustainable path. Our study shows that such radical changes can threaten relationships with stakeholders who identify with the venture, such as user communities, thus jeopardizing the venture's viability. Through the concept of identification reset work, we unpack how ventures can tackle this key challenge. We hope that our research will spur more research into the critical issue of how new ventures manage the identification of key stakeholders. 


\section{APPENDIX}

Table 1: Data Overview

Data Type

\section{Interview Data}

Interviews with Impossible staff and retailers Interviews with community members

\section{Archival Data}

Selected tweets

Impossible newsletters

Documentary film footage (mins.)

Press articles

Impossible blog posts (selected)

Impossible press releases

Books and documentaries

\section{Amount Role in Analysis}

$40 \quad$ Understand how and why venture acted

$34 \quad$ Understand how and why community reacted

1,570 Understand how community reacted

650 Understand how venture acted

388 Nuance venture actions and community reactions

206 Provide contextual information

131 Understand how venture acted

90 Provide contextual information

7 Provide contextual information

\section{Participant Observation Data}

Fieldwork at Impossible (weeks)

$8 \quad$ Nuance venture actions and community reactions 
Table 2: Dimensions, Themes, Categories and Quotes

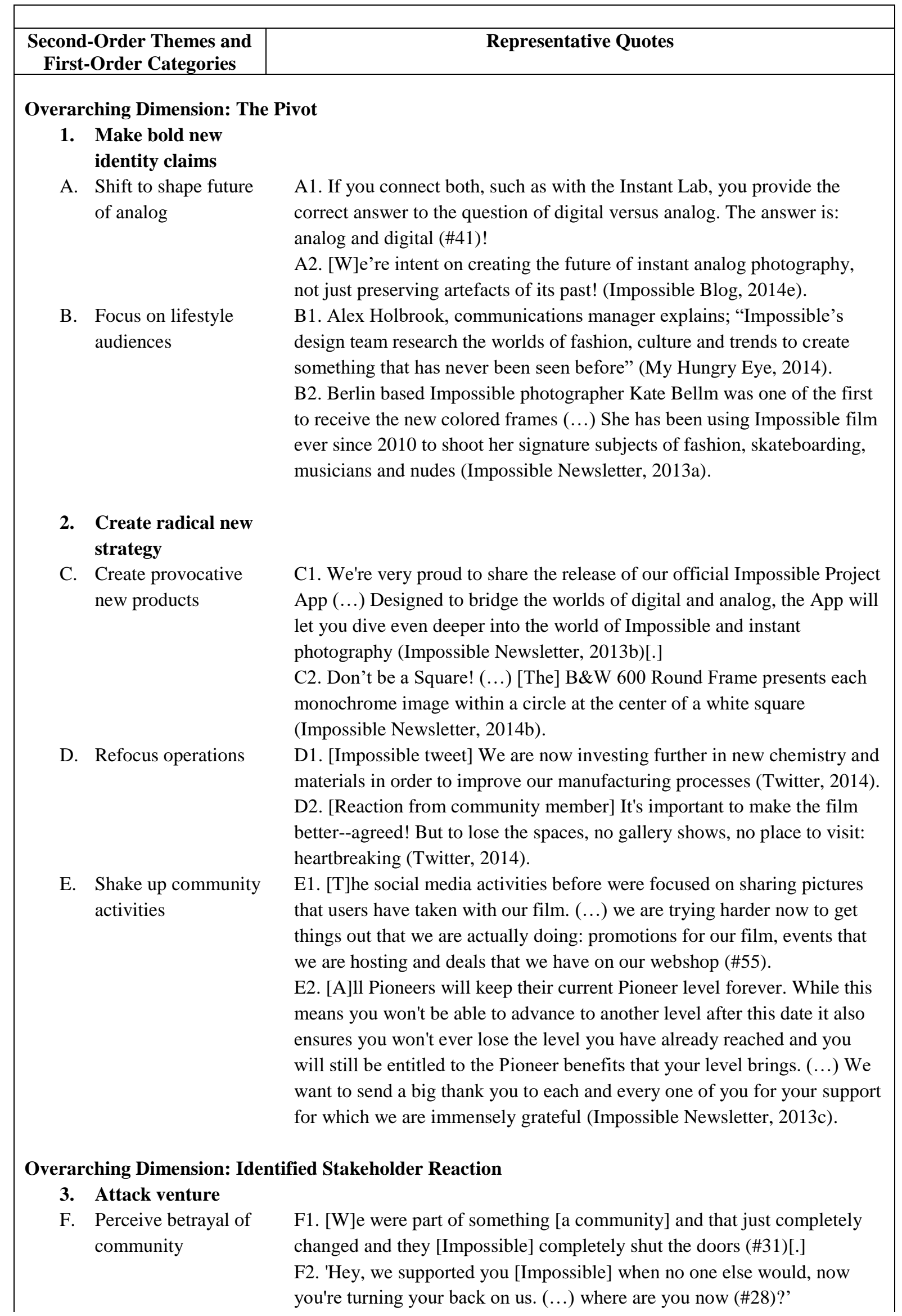


G. Fight Impossible

4. Doubt venture

H. Experience anxiety

I. Stress no longer feeling valued

\section{Disengage from} venture

J. Accept venture's genuineness

K. Respect efforts for film

L. Make peace with change and exit

6. Resume support for venture

M. Feel reverence for film progress

N. Understand challenges and defend venture
G1. There were thousands of tweets in anger about this. When I say there was a maelstrom, they were being attacked (...) photographers talking about how they are not gonna shoot Impossible [film] anymore (\#10)[.] G2. People, you still buying Impossible Project film...? You're aware it's shit, right (Twitter, 2016)?

H1. [A] lot of people didn't know where to go and that led to confusion, and disenfranchisement from Impossible as a company (\#6).

$\mathrm{H} 2$. [T] hey were still very angry and confused but I think it took probably a good year for them to start to come around to this new way (\#53).

I1. [A] lot of early adopters feel that Impossible doesn't care about them anymore (Twitter, 2014).

I2. [J] ust don't take away the personal touch (Twitter, 2013).

J1. I think some of the things they were saying were like: "We need to become more professional" or "We are in a really bad shape." (...) It feels like they are doing more, at least from the factory side, which is good. (...) I don't think Impossible will last a very long time. (\#7).

J2. I did get really upset, but then I had to remind myself (...) [that] they were still making something that a lot of people (...) enjoy (\#22).

$\mathrm{K} 1$. It has taken them a long time to rebuild the relationships and with many they haven't achieved that. They have tried to do this through the product now. (...) they can rely on that to stand on (\#6).

K2. I was actually impressed with how much progress they made (\#26)[.]

L1. [T]hey are a non-entity to me. I have basically forgotten about them (Twitter, 2015)[.]

L2. I probably spent around $\$ 3000$ with Impossible Project in $2011 ;(\ldots)$ when I buy film [now] it's one or two packs here and there (\#6).

M1. Many thanks to @Impossible_HQ for keeping instant film alive for all of us. The formulas keep getting better and better (Twitter, 2014)[1]

M2. @Impossible_HQ (...) () love this film (Twitter, 2015).

N1. I understand that (...) [Impossible] is trying to stay in solvency (\#3).

$\mathrm{N} 2$. They are a very small company and have a limited number of resources. (...) I am grateful that they are doing something so unique and that they have figured out a way to create a successful business. That has to be a struggle. They have to look for ways to expand (...) and to engage people who might normally not consider shooting with this film (\#1).

\section{Overarching Dimension: Identification Reset Work}

7. Seek empathy for venture challenges

O. Stress technical struggles
O1. But are there times when the project feels genuinely impossible? "Every day," says [Impossible CEO] Smolokowski. "At one point (...) a supplier of ours stopped making a chemical that was critical (...) the team managed to invent a new substitute just a few days before it would have completely stopped film production" (Dazed Digital, 2015). 
P. Remind about mortal threat

R. Celebrate analog in a digital world

\section{Mythologize} technology

Q. Link to technology's origins
O2. Every single day we make experimental film. It's all hands-on work. (...) It takes many months or years to be able to develop some of these improvements in chemistry (Impossible Youtube Channel, 2015b). $\mathrm{P} 1$. [O] ur focus has had to be on re-thinking nearly every aspect of Impossible's operations to ensure the company's long-term success (Impossible Newsletter, 2014b) [.]

$\mathrm{P} 2$. Impossible executive: this is unquestionably the most challenging period we have ever had in the life of the company[.] Community leader in response: "I know your goal. (...) We are the basic target [audience], of course, but you want a main target [audience] larger than us to survive and I can understand [that] (Exchange between Impossible and community group, 2014. Transcript of footage for documentary about Impossible).

Q1. [Impossible employee] Jos Ridderhof (...) loves the [Polaroid] SX-70 [camera] so much that he decided to ink it forever on his skin with a tattoo (Impossible Blog, 2014f)

Q2. Stephen provided the direct link between The Impossible Project and the original Polaroid processes (James, 2016).

R1. [Digital] will never be that tangible moment that you can hold in your hand right then and there and that can never be exactly replicated. It's what makes it [analog] so unique (Impossible Blog, 2014i).

R2. [I]n the photographic medium, there's something irrepressible about analog that digital cannot match (Impossible Blog, 2014j).

\section{Mythologize commitment to product}

S. Stress devotion to product

T. Show progress in tackling struggles

U. Enlist credible supporters
S1. We've doubled down on R\&D, giving Stephen Herchen \& his team the resources needed to take the next big step (Twitter, 2015).

$\mathrm{S} 2$. [T] he first responsibility we have to all you guys is to make a really good black and white film, and a really good color film. (...) that's our whole life at the moment. I feel incredibly passionate and driven about it (Executive in conversation with community members in 2014. Transcript of footage for documentary about Impossible)[.]

T1. [W] will launch the first major change to our B\&W film formula (...) it will be our best film to date - sharper, with blacker blacks and whiter whites. (...) I want to thank our factory and R\&D teams (...) [who] put their hearts and souls into this film (Impossible Newsletter, 2015)[.] T2. In our film for Spectra/Image we are missing a sufficiently thin rail material. (...) One strategy is the continued search and testing of new adhesives (...) The other is making a change to the B\&W paste so that it can work with a thicker rail (Pdexposures, 2014b).

U1. Impossible has long wanted to connect more directly with the founder of the forum (...) [Comment by forum organizer:] "I am really glad to have met the faces behind Impossible in Berlin. (...) I enjoyed talking about Impossible products and plans for the future" (Impossible Blog, 2014k). U2. [T]his week we have a very special guest on the Pdexposures podcast: Alex Holbrook, Marketing Communications Manager for the Impossible Project. (Pdexposures, 2014c)[.] 
Table 3: Overview of Impossible's Pivot

Before pivot (pre-2013) After pivot (2013 onwards)

\begin{tabular}{lll}
\hline Identity & & \\
\hline Key identity claims & $\begin{array}{l}\text { Analog instant film provider } \\
\text { that focuses on community } \\
\text { niche. }\end{array}$ & $\begin{array}{l}\text { Analog-digital company that } \\
\text { wants to make analog instant } \\
\text { photography relevant to } \\
\text { digital world and focuses on } \\
\end{array}$ \\
& mass-market audiences.
\end{tabular}

\begin{tabular}{|c|c|c|}
\hline Strategy & & \\
\hline Product focus & $\begin{array}{l}\text { Production of films with } \\
\text { primary emphasis on film } \\
\text { for classic Polaroid cameras. } \\
\text { Focus on classic film } \\
\text { designs. }\end{array}$ & $\begin{array}{l}\text { Production of films and } \\
\text { hardware with primary } \\
\text { emphasis on analog-digital } \\
\text { crossover hardware (e.g., } \\
\text { "Instant Lab"). Launch of a } \\
\text { variety of special edition } \\
\text { films that depart from } \\
\text { classic design (e.g., colored, } \\
\text { round and patterned frames). }\end{array}$ \\
\hline Focus of operations & $\begin{array}{l}\text { From head office in Vienna, } \\
\text { Austria, venture expands } \\
\text { shop and gallery spaces and } \\
\text { focuses on sales through } \\
\text { photography retailers. }\end{array}$ & $\begin{array}{l}\text { From new head office in } \\
\text { Berlin, Germany, the } \\
\text { venture closes shop and } \\
\text { gallery spaces to instead } \\
\text { build new digital design } \\
\text { team, launch analog-digital } \\
\text { hardware, prioritize film } \\
\text { improvements, and focus on } \\
\text { fashion retailers. }\end{array}$ \\
\hline Community interactions & $\begin{array}{l}\text { In-depth engagement with } \\
\text { niche user community } \\
\text { through a variety of } \\
\text { channels, including } \\
\text { extensive social media } \\
\text { interactions, dedicated shop } \\
\text { and gallery spaces and } \\
\text { specialist photo retailers. }\end{array}$ & $\begin{array}{l}\text { New focus on mass-market } \\
\text { audiences with interest in } \\
\text { fashion and lifestyle. } \\
\text { Reduction in interactions } \\
\text { with niche user community } \\
\text { (e.g., fewer digital channels, } \\
\text { less intensity, no longer } \\
\text { interaction through } \\
\text { Impossible gallery spaces). }\end{array}$ \\
\hline
\end{tabular}




\section{Table 4: Further Quotes by Impossible Staff about the Importance of Community}

\section{Members for Impossible}

[T] he community is who is buying our film. There are people who are extremely enthusiastic about the products we develop [at Impossible]. They are very opinionated as well. It's a very fine line. On the one hand, you must never alienate these people by telling them: "You have no say in what we do. We have to look at what's best for the business." On the other hand you have to be very careful not to react to every whim of the community. (...) Since Impossible film is still a premium niche product, it's very important to have a tightly-knit community that feels some kind of belonging and kinship with each other. (...) This is the thing: the passion swings both ways (\#57).

We see a huge core of our user base being these passionate users of our materials (\#44)[.]

The community was one hundred percent the reason that Impossible exists today. (...) It was only by drawing them together that Impossible was able to make enough money to create its first film. (...) the money that we will make selling this film is the money that will finance all the research and development that we need to do to make Impossible film, to make new film. (...) Well, the simple fact was that the community was the only choice that we had, the only people we could turn to when the first films were released - the first test films. (...) we devised (...) the Pioneer Program as a way to reward the people who bought these earliest films. And these were the members of the community that felt most strongly that they could lend their support in a real way, almost like investors (\#48).

It was somehow a big project that said, "Hey, come on. We all together have to give it a try." (...) This was the spirit and with these Pioneers, it was somehow a big global movement that said, "Okay, we stand up together and fight that this material will never disappear." Yes, we had the factory and we had the machines, but I felt that it was a big community making this Impossible project possible every day. (...) They [Pioneers] were not crucial they were essential for film development. (...) This [having the Pioneer community] was super important (\#42)[.]

All that ties in together basically the one running theme was that without this community we [Impossible] wouldn't exist (\#49).

It's very important to keep them [your community] engaged. (...) your audience is like a triangle: the bottom, which gives stability, are your key and core supporters. If you take that away, then everything else becomes a bit shaken. (...) If the experts are saying that the product is really bad, then they [new audiences] are not gonna buy into it (\#50).

[L]ooking at the size of the company we had, they are almost like spokespeople for us. (...) We had so many people come to us because one of their friends told them about it and that is how Impossible actually started selling more and more products, was simply because enthusiastic people got other people excited about it (\#52).

Right now, the IMPOSSIBLE Project seems like one great folly, burdened by growing pains (...). In simple terms, the company needs more people to buy hardware and film (...). Until then, the IMPOSSIBLE Project must rely on early adopters, enthusiasts, and creative types (Spence, 2013). 


\section{Figure 1: Timeline}

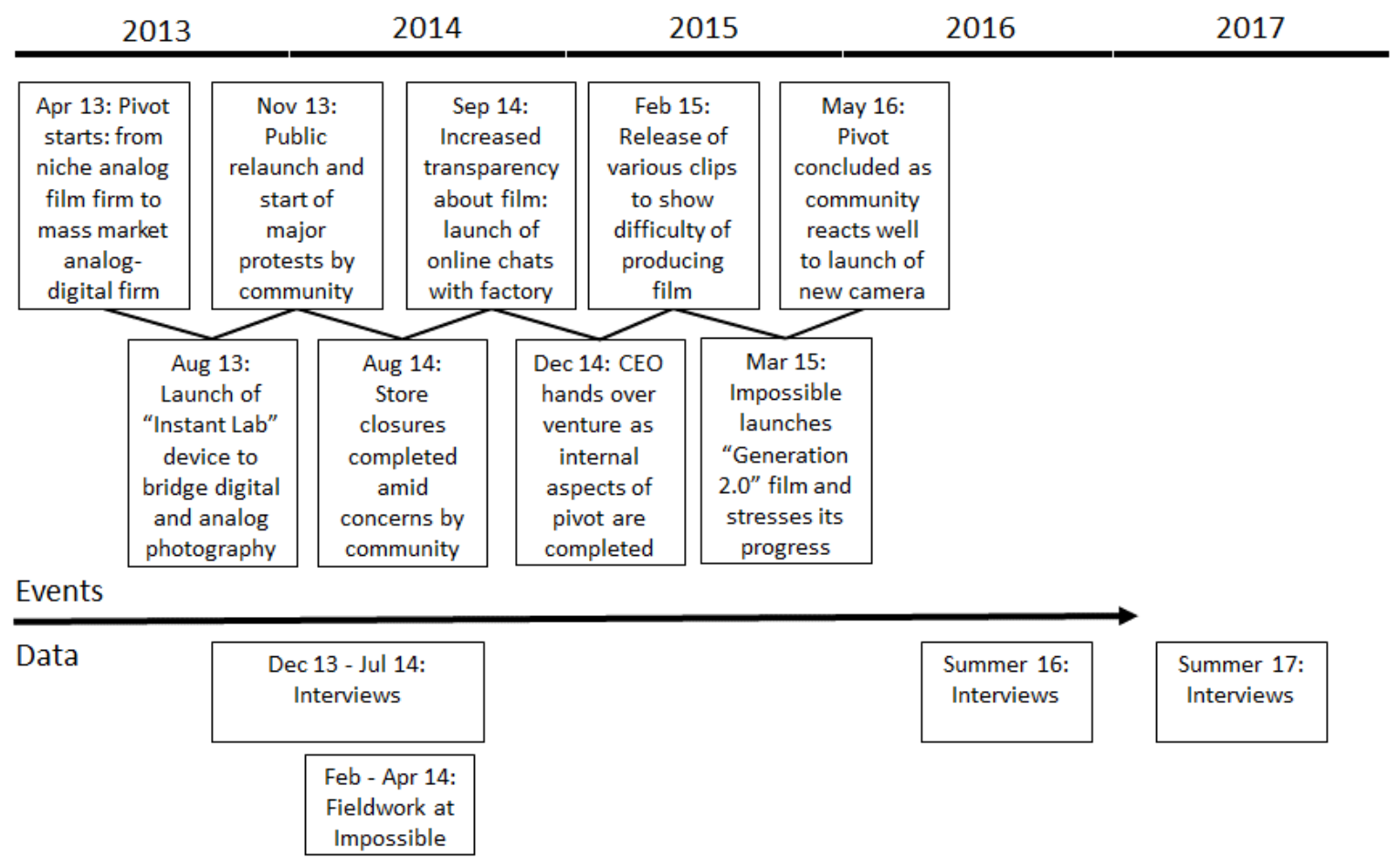

Jan 13 - Dec 16: Impossible's media and social media activities (e.g., tweets, newsletters)

Jan 13 - Dec 16: Media reporting about and community reactions to Impossible (e.g., articles, blogs) 
Figure 2: Data Structure

First-order codes

A. Shift to shape future of analog

B. Focus on lifestyle audiences

C. Create provocative new products

D. Refocus operations

E. Shake up community activities

F. Perceive betrayal of community

G. Fight Impossible

H. Experience anxiety

I. Stress no longer feeling valued

J. Accept venture's genuineness

K. Respect efforts for film

L. Make peace with change and exit

$M$. Feel reverence for film progress

$\mathrm{N}$. Understand challenges and defend venture

O. Stress technical struggles

P. Remind about mortal threat

Q. Link to technology's origins

R. Celebrate analog in digital world

S. Stress devotion to product

T. Show progress in tackling struggles

U. Enlist credible supporters
Second-order

themes

1. Make bold new identity claims

2. Create radical new strategy

3. Attack venture

. Attack venture

4. Doubt venture

5. Disengage from venture

6. Resume support for venture

7. Seek empathy for venture challenges

8. Mythologize technology

9. Mythologize commitment to product
Aggregate theoretical dimensions

\section{Enact pivot}

Stakeholder reaction

\section{Identification} reset work 
Figure 3: Model of Stakeholder Identification Management during New Venture Pivots

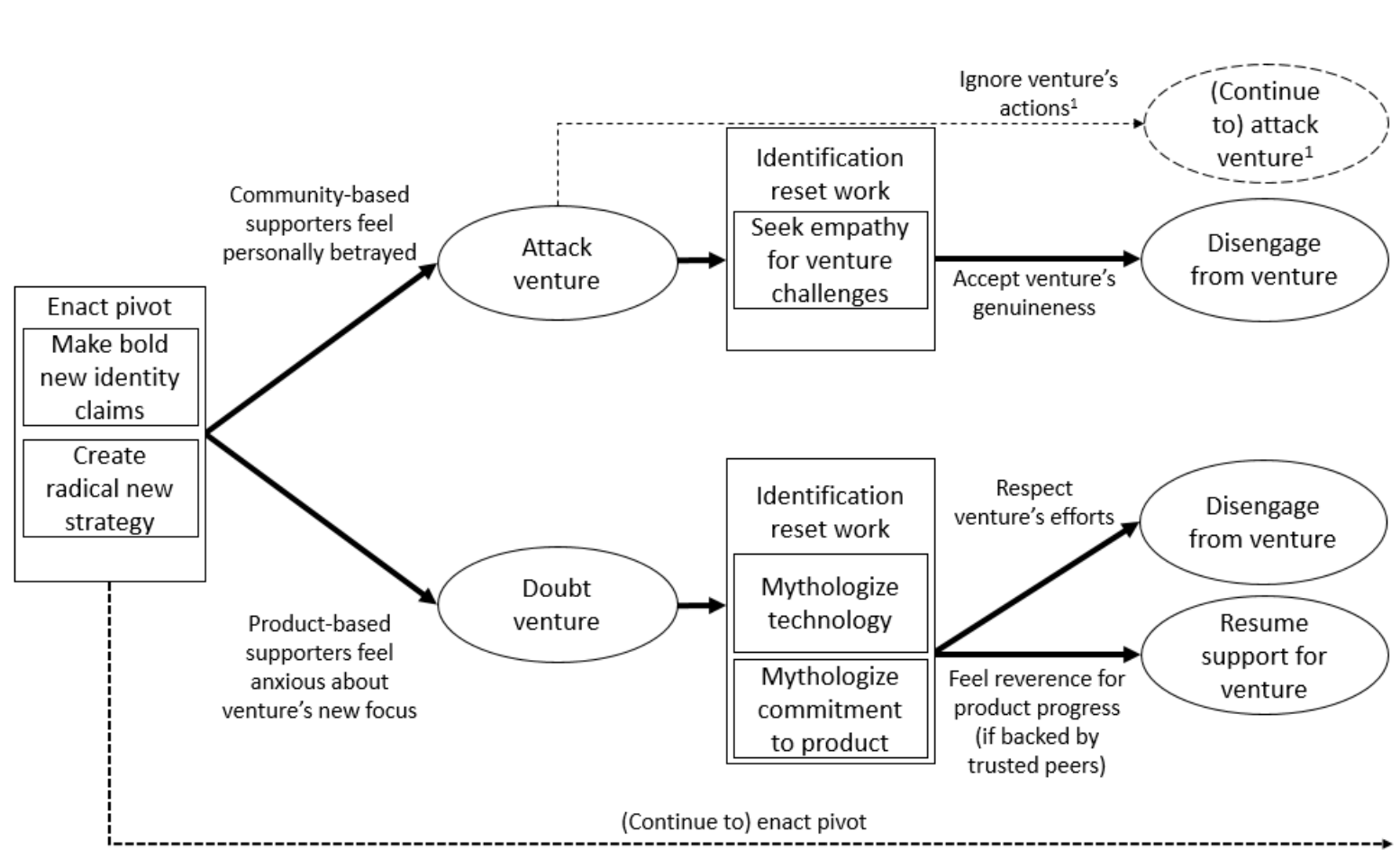

Legend

Venture actions $\bigcirc \quad$ Stakeholder reactions ${ }^{1}$

${ }^{1}$ The finely dashed line and oval denote a rare stakeholder reaction. 


\section{REFERENCES}

Albert, S., \& Whetten, D. A. 1985. Organizational identity. In L. L. Cummings \& B. M. Staw (Eds.), Research in Organizational Behavior, vol. 7: 263-295. Greenwich, CT: JAI Press.

Aldrich, H. E., \& Fiol, C. M. 1994. Fools rush in? The institutional context of industry creation. Academy of Management Review, 19(4): 645-670.

Ashforth, B. E., Harrison, S. H., \& Corley, K. G. 2008. Identification in Organizations: An Examination of Four Fundamental Questions. Journal of Management, 34(3): 325374.

Ashforth, B. E., Schinoff, B. S., \& Brickson, S. forthcoming. "My Company is Friendly," "Mine's a Rebel": Anthropomorphism and Shifting Organizational Identity from "What" to "Who." Academy of Management Review. https://doi.org/10.5465/amr.2016.0496.

Atkins. 2016, February 11. Uber - it's a bit like Marmite. http://www.atkinsglobal.co.uk/enGB/angles/all-angles/uber-a-bit-like-marmite.

Bartel, C. A., Baldi, C., \& Dukerich, J. M. 2016. Fostering Stakeholder Identification Through Expressed Organizational Identities. In M. G. Pratt, M. Schultz, B. E. Ashforth, \& D. Ravasi (Eds.), The Oxford Handbook of Organizational Identity: 474-493. Oxford University Press.

Besharov, M. L. 2014. The relational ecology of identification: How organizational identification emerges when individuals hold divergent values. Academy of Management Journal, 57(5): 1485-1512.

Blank, S. 2013. Why the lean start-up changes everything. Harvard Business Review, 91(5): 63-72.

Bradshaw, T. 2009, August 14. Bringing back Polaroid's instant film. Financial Times.

Carroll, G. R., \& Wheaton, D. R. 2009. The organizational construction of authenticity: An examination of contemporary food and dining in the US. Research in Organizational Behavior, 29: 255-282.

Cook, J. 2015, November 18. SoundCloud's loyal users are starting to lose faith in the site Business Insider. Business Insider. http://uk.businessinsider.com/soundclouds-loyalusers-are-starting-to-lose-faith-in-the-site-2015-11.

Corley, K. G., \& Gioia, D. A. 2004. Identity ambiguity and change in the wake of a corporate spin-off. Administrative Science Quarterly, 49(2): 173-208.

Cornwell, T. B., Howard-Grenville, J., \& Hampel, C. 2018. The Company You Keep: How an Organization's Horizontal Partnerships affect Employee Organizational Identification. Academy of Management Review, 43(4): 772-791.

Dazed Digital. 2015, December 7. Analog photography has been given a modern day boost. https://www.dazeddigital.com/beauty/photography/article/28745/1/analogphotography-has-been-given-a-modern-day-boost.

Dew, N., \& Sarasvathy, S. D. 2007. Innovations, Stakeholders \& Entrepreneurship. Journal of Business Ethics, 74(3): 267-283.

Drori, I., Honig, B., \& Sheaffer, Z. 2009. The life cycle of an internet firm: Scripts, legitimacy, and identity. Entrepreneurship Theory and Practice, 33(3): 715-738. 
Dukerich, J. M., Kramer, R. M., \& Parks, J. M. 1998. The dark side of organizational identification. Identity in organizations: Building theory through conversations: 245-256. Thousand Oaks, CA: SAGE Publications.

Dutton, J. E., \& Dukerich, J. M. 1991. Keeping an eye on the mirror: Image and identity in organizational adaptation. Academy of Management Journal, 34(3): 517-554.

Eisenhardt, K. M., \& Graebner, M. E. 2007. Theory building from cases: Opportunities and challenges. Academy of Management Journal, 50(1): 25-32.

Elder, R. 2016, August 18. Yik Yak pivots dangerously away from its core identity. Business Insider. http://uk.businessinsider.com/yik-yak-pivots-dangerously-away-from-itscore-identity-2016-8.

Elsbach, K. D., \& Bhattacharya, C. B. 2001. Defining who you are by what you're not: Organizational disidentification and the National Rifle Association. Organization Science, 12(4): 393-413.

Erkama, N., \& Vaara, E. 2010. Struggles over legitimacy in global organizational restructuring: A rhetorical perspective on legitimation strategies and dynamics in a shutdown case. Organization Studies, 31(7): 813-839.

Eury, J. L., Kreiner, G. E., Trevino, L. K., \& Gioia, D. A. 2018. The Past is Not Dead: Legacy Identification and Alumni Ambivalence in the Wake of the Sandusky Scandal at Penn State. Academy of Management Journal, 61(3): 826-856.

Fiol, C. M. 2002. Capitalizing on paradox: The role of language in transforming organizational identities. Organization Science, 13(6): 653-666.

Fiol, C. M., Pratt, M. G., \& O’Connor, E. J. 2009. Managing intractable identity conflicts. Academy of Management Review, 34(1): 32-55.

Fisher, G., Kotha, S., \& Lahiri, A. 2016. Changing with the times: An integrated view of identity, legitimacy and new venture life cycles. Academy of Management Review, 41(3): 383-409.

Garud, R., Schildt, H. A., \& Lant, T. K. 2014. Entrepreneurial storytelling, future expectations, and the paradox of legitimacy. Organization Science, 25(5): 14791492.

Gioia, D. A., \& Chittipeddi, K. 1991. Sensemaking and sensegiving in strategic change initiation. Strategic Management Journal, 12(6): 433-448.

Gioia, D. A., Patvardhan, S. D., Hamilton, A. L., \& Corley, K. G. 2013. Organizational identity formation and change. Academy of Management Annals, 7(1): 123-193.

Gioia, D. A., Price, K. N., Hamilton, A. L., \& Thomas, J. B. 2010. Forging an identity: An insider-outsider study of processes involved in the formation of organizational identity. Administrative Science Quarterly, 55(1): 1-46.

Glaser, B. G., \& Strauss, A. L. 2009. The Discovery of Grounded Theory. New Brunswick, NJ: Transaction Publishers.

Grimes, M. G. 2018. The Pivot: How Founders Respond to Feedback Through Idea and Identity Work. Academy of Management Journal, 61(5): 1692-1717.

Gutierrez, B., Howard-Grenville, J., \& Scully, M. A. 2010. The faithful rise up: Split identification and an unlikely change effort. Academy of Management Journal, 53(4): 673-699. 
Hampel, C. E., \& Tracey, P. 2017. How Organizations Move From Stigma to Legitimacy: The Case of Cook's Travel Agency in Victorian Britain. Academy of Management Journal, 60(6): 2175-2207.

Harrison, S. H., \& Corley, K. G. 2011. Clean climbing, carabiners, and cultural cultivation: Developing an open-systems perspective of culture. Organization Science, 22(2): 391-412.

Helms, W., \& Patterson, K. 2014. Eliciting Acceptance for "Illicit" Organizations: The Positive Implications of Stigma for MMA Organizations. Academy of Management Journal, 57(5): 1453-1484.

Honig, B. 2004. Entrepreneurship education: Toward a model of contingency-based business planning. Academy of Management Learning \& Education, 3(3): 258-273.

Howard-Grenville, J., Metzger, M. L., \& Meyer, A. D. 2013. Rekindling the flame: Processes of identity resurrection. Academy of Management Journal, 56(1): 113-136.

Huy, Q. N., Corley, K. G., \& Kraatz, M. S. 2014. From support to mutiny: Shifting legitimacy judgments and emotional reactions impacting the implementation of radical change. Academy of Management Journal, 57(6): 1650-1680.

Impossible Blog. 2014a, June 25. Impossible goes Ultraviolence with Lana Del Rey! https://blog.the-impossible-project.com/.

Impossible Blog. 2014b, December 10. A New Chairman, A New CEO For Impossible. https://blog.the-impossible-project.com/.

Impossible Blog. 2014c, March 4. Impossible Interviews \#10 - Oliver Heinzel. https://blog.the-impossible-project.com/.

Impossible Blog. 2014d, November 18. 1,000,000 Instant Films - An Historic Impossible Milestone. https://blog.the-impossible-project.com/.

Impossible Blog. 2014e, January 30. Impossible Interviews \#7 - Alex Holbrook. https://blog.the-impossible-project.com/.

Impossible Blog. 2014f, May 15. Video: Impossible Turns Polaroid Collectibles Into Working Cameras. https://blog.the-impossible-project.com/.

Impossible Blog. 2014g, September 12. Meet Impossible USA: Liora Klein, Camera Manufacturing Manager. https://blog.the-impossible-project.com/.

Impossible Blog. 2014h, September 5. Meet Impossible USA: Frank Love, Director of US Operations. https://blog.the-impossible-project.com/.

Impossible Blog. 2014i, July 17. Polaroid Passion at Impossible HQ. https://blog.theimpossible-project.com/.

Impossible Magazine. 2015, October 5. Impossible Color Film Update 2015. Impossible Newsletter. 2013a, November 20. Impossible Color Frames are Finally Here. Impossible Newsletter. 2013b, August 6. Introducing... The Impossible Project App. Impossible Newsletter. 2013c, August 6. An Important Message for our Pioneers. Impossible Newsletter. 2014a, September 15. An All-New Impossible B\&W 600 Film. Impossible Newsletter. 2014b, October 13. A Letter from Stephen Herchen, Chief Technical Officer.

Impossible Newsletter. 2015, March 9. An Update from Impossible HQ. Impossible Youtube Channel. 2015a, December 7. A Brief History of the Impossible Project. https://www.youtube.com/watch?v=MM5k4B1C7cs. 
Impossible Youtube Channel. 2015b, March 26. A New Generation of Black and White Impossible Instant Film. https://www.youtube.com/watch? $=x$ FkBKfYDjLI\&t=1s. James, A. 2016, April 15. The Impossible Project: How two men saved Polaroid. Amateur Photographer. https://www.amateurphotographer.co.uk/latest/articles/the-impossibleproject-2-73695.

Jawahar, I. M., \& McLaughlin, G. L. 2001. Toward a descriptive stakeholder theory: An organizational life cycle approach. Academy of Management Review, 26(3): 397414.

Klebahn, P., \& O'Connor, C. 2011, February 28. The Strategic Pivot: Rules for Entrepreneurs and Other Innovators. Harvard Business Review. https://hbr.org/2011/02/how-andwhen-to-pivot-rules-fo.

Kreiner, G. E., \& Ashforth, B. E. 2004. Evidence toward an expanded model of organizational identification. Journal of Organizational Behavior, 25(1): 1-27.

Kreiner, G. E., Hollensbe, E., Sheep, M. L., Smith, B. R., \& Kataria, N. 2015. Elasticity and the Dialectic Tensions of Organizational Identity: How Can We Hold Together While We Are Pulling Apart? Academy of Management Journal, 58(4): 981-1011.

Kunisch, S., Bartunek, J., Mueller, J., \& Huy, Q. 2017. Time in Strategic Change Research. Academy of Management Annals, 11(2): 1005-1064.

Lakhani, K. R., \& Kanji, Z. 2008. Threadless: The Business of Community. Harvard Business School Press, Case 608-707. http://www.hbs.edu/faculty/Pages/item.aspx?num=36152.

Langley, A. 1999. Strategies for theorizing from process data. Academy of Management Review, 24(4): 691-710.

Laplume, A. O., Sonpar, K., \& Litz, R. A. 2008. Stakeholder theory: Reviewing a theory that moves us. Journal of Management, 34(6): 1152-1189.

Lincoln, Y. S., \& Guba, E. G. 1985. Naturalistic Inquiry. Thousand Oaks, CA: Sage.

Mael, F., \& Ashforth, B. E. 1992. Alumni and their alma mater: A partial test of the reformulated model of organizational identification. Journal of Organizational Behavior, 13(2): 103-123.

Mantere, S., Aula, P., Schildt, H., \& Vaara, E. 2013. Narrative attributions of entrepreneurial failure. Journal of Business Venturing, 28(4): 459-473.

Massa, F. G. 2016. Recasting Community for Online Resisting Work. In D. Courpasson \& S. Vallas (Eds.), The SAGE Handbook of Resistance: 247-268. Thousand Oaks, CA: SAGE.

Massa, F. G. 2017. Guardians of the Internet: Building and Sustaining the Anonymous Online Community. Organization Studies, 38(7): 959-988.

Massa, F. G., Helms, W., Voronov, M., \& Wang, L. 2017. Emotions Uncorked: Inspiring Evangelism for the Emerging Practice of Cool Climate Winemaking in Ontario. Academy of Management Journal, 60(2): 461-499.

Mathies, D. 2017, September 13. Polaroid lives again with new brand and OneStep 2 instant camera. Digital Trends. https://www.digitaltrends.com/photography/polaroidoriginals-onestep- $2 /$. 
McMullen, J. S. 2017. Are you pivoting away your passion? The hidden danger of assuming customer sovereignty in entrepreneurial value creation. Business Horizons, 60(4): 427-430.

Mitchell, R. K., \& Cohen, B. 2006. Stakeholder Theory and the Entrepreneurial Firm. Journal of Small Business Strategy, 17(1): 1-16.

My Hungry Eye. 2014, August 12. New Special Edition Film from IMPOSSIBLE. http://hungryeyejournal.com/new-special-edition-film-from-impossible-colour-600poison-paradise/.

Nag, R., Corley, K. G., \& Gioia, D. A. 2007. The intersection of organizational identity, knowledge, and practice: Attempting strategic change via knowledge grafting. Academy of Management Journal, 50(4): 821-847.

Navis, C., \& Glynn, M. A. 2011. Legitimate distinctiveness and the entrepreneurial identity: Influence on investor judgments of new venture plausibility. Academy of Management Review, 36(3): 479-499.

Nazar, J. 2013, October 8. 14 Famous Business Pivots. Forbes. https://www.forbes.com/sites/jasonnazar/2013/10/08/14-famous-business-pivots/.

Nicholls-Nixon, C. L., Cooper, A. C., \& Woo, C. Y. 2000. Strategic Experimentation: Understanding Change and Performance in New Ventures. Journal of Business Venturing, 15(5): 493-521.

Nobel, C. 2011. Teaching a "Lean Startup" Strategy. HBS Working Knowledge, 1-2.

Parmar, B. L., Freeman, R. E., Harrison, J. S., Wicks, A. C., Purnell, L., et al. 2010. Stakeholder Theory: The State of the Art. The Academy of Management Annals, 4(1): 403-445.

Pdexposures. 2014a, October 8. Pdexposures Podcast Episode 40 - Everything Instant, pt. 2 (and a bit more). http://www.pdexposures.com/pdexposures-podcast-episode-40everything-instant-pt-2-bit/.

Pdexposures. 2014b, February 4. Impossible Spectra Update. http://www.pdexposures.com/impossible-spectra-update/.

Pdexposures. 2014c, March 18. Pdexposures Podcast Episode 28 - An Impossible Visitor. http://www.pdexposures.com/pdexposures-podcast-episode-28-an-impossible-visitor/. Penenberg, A. L. 2012, May 2. Enter The Pivot: The Critical Course Corrections Of Flickr, Fab.com, And More. Fast Company. https://www.fastcompany.com/1834196/enterpivot-critical-course-corrections-flickr-fabcom-and-more.

Petriglieri, J. L. 2015. Co-creating Relationship Repair: Pathways to Reconstructing Destabilized Organizational Identification. Administrative Science Quarterly, 60(3): 518-557.

Pratt, M. G. 1998. To Be or Not to Be? Central Questions in Organizational Identification. In D. A. Whetten \& P. C. Godfrey (Eds.), Identity in Organizations: 171-207. Thousand Oaks, CA: SAGE Publications.

Pratt, M. G. 2000. The good, the bad, and the ambivalent: Managing identification among Amway distributors. Administrative Science Quarterly, 45(3): 456-493.

Ram, A. 2017, July 6. SoundCloud cuts $40 \%$ of workforce and shuts half its offices. Financial Times. https://www.ft.com/content/1065213c-6269-11e7-91a7$502 f 7 e e 26895$. 
Ries, E. 2011. The Lean Startup: How Constant Innovation Creates Radically Successful Businesses. London, UK: Portfolio Penguin.

Rossner, M., \& Meher, M. 2014. Emotions in ritual theories. Handbook of the Sociology of Emotions: Volume II: 199-220. Springer.

Sax, D. 2016, April 11. The Company That's Keeping the Polaroid Legacy Alive. Bloomberg.com. http://www.bloomberg.com/features/2016-design/a/oskarsmolokowski/.

Sinibaldi, C., \& Stone, M.-L. 2018, September 18. Strictly analogue: Polaroid's past, present and future - a photo essay. The Guardian.

https://www.theguardian.com/artanddesign/2018/sep/18/strictly-analogue-polaroidspast-present-and-future-a-photo-essay.

Snapitseeit. 2014, August 8. Time Zero. http://snapitseeit.com/.

Spence, N. 2013, September 12. Hands On And Up Close With The IMPOSSIBLE Project For iPhone - By ... TheAppWhisperer. http://theappwhisperer.com/2013/09/hands-onand-up-close-with-the-impossible-project-for-iphone-by-nick-spence/.

Stinchcombe, A. 1965. Social structure and organizations. In J. March (Ed.), The Handbook of Organizations: 1425193.

Suchman, M. C. 1995. Managing legitimacy: Strategic and institutional approaches. Academy of Management Review, 20(3): 571-610.

Suddaby, R., \& Greenwood, R. 2005. Rhetorical strategies of legitimacy. Administrative Science Quarterly, 50(1): 35-67.

Toubiana, M., \& Zietsma, C. 2017. The Message is on the Wall? Emotions, Social Media and the Dynamics of Institutional Complexity. Academy of Management Journal, 60(3): 922-953.

Vaara, E., \& Tienari, J. 2010. On the Narrative Construction of Multinational Corporations: An Antenarrative Analysis of Legitimation and Resistance in a Cross-Border Merger. Organization Science, 22(2): 370-390.

Vaara, E., Tienari, J., \& Laurila, J. 2006. Pulp and paper fiction: On the discursive legitimation of global industrial restructuring. Organization Studies, 27(6): 789-813. van Werven, R., Bouwmeester, O., \& Cornelissen, J. P. 2015. The power of arguments: How entrepreneurs convince stakeholders of the legitimate distinctiveness of their ventures. Journal of Business Venturing, 30(4): 616-631.

Von Hippel, E. 2001. Innovation by user communities: Learning from open-source software. MIT Sloan Management Review, 42(4): 82.

Weber, K., Heinze, K. L., \& DeSoucey, M. 2008. Forage for thought: Mobilizing codes in the movement for grass-fed meat and dairy products. Administrative Science Quarterly, 53(3): 529-567.

York, J. G., Hargrave, T. J., \& Pacheco, D. F. 2016. Converging winds: Logic hybridization in the Colorado wind energy field. Academy of Management Journal, 59(2): 579 610.

Zimmerman, M. A., \& Zeitz, G. J. 2002. Beyond Survival: Achieving New Venture Growth by Building Legitimacy. Academy of Management Review, 27(3): 414-431.

Zollner, M. 2016, October 27. Oskar Smolokowski. Fotomagazin. https://www.fotomagazin.de/bild/interview/oskar-smolokowski. 


\section{AUTHOR BIOGRAPHIES}

Christian E. Hampel (c.hampel@imperial.ac.uk) is an assistant professor of entrepreneurship and strategy at Imperial College Business School. He received his $\mathrm{PhD}$ from the University of Cambridge Judge Business School. His research explores how new ventures experience and manage social evaluations (e.g., identification, stigma, legitimacy).

Paul Tracey (p.tracey@jbs.cam.ac.uk) is professor of innovation and organization and codirector of the Centre for Social Innovation at the University of Cambridge Judge Business School. He is also professor of entrepreneurship at the Department of Management and Marketing, University of Melbourne. He received his $\mathrm{PhD}$ from the University of Stirling. Klaus Weber (klausweber@kellogg.northwestern.edu) is a professor of management and organizations at the Kellogg School of Management, Northwestern University. He received his Ph.D. in organization and management theory from the University of Michigan. His research uses cultural and institutional analysis to study the intersection of social movements and the economy, the political economy of globalization, and sustainability. 